IZA DP No. 9383

The Effect of Language on Economic Behavior: Experimental Evidence from Children's Intertemporal Choices

Matthias Sutter

Silvia Angerer

Daniela Glätzle-Rützler

Philipp Lergetporer

September 2015 


\title{
The Effect of Language on Economic Behavior: Experimental Evidence from Children's Intertemporal Choices
}

\author{
Matthias Sutter \\ University of Cologne, University of Innsbruck, IZA and CESifo \\ Silvia Angerer \\ IHS Carinthia, Klagenfurt \\ Daniela Glätzle-Rützler \\ University of Innsbruck \\ Philipp Lergetporer \\ Ifo Institute at the University of Munich and CESifo
}

Discussion Paper No. 9383

September 2015

\author{
IZA \\ P.O. Box 7240 \\ 53072 Bonn \\ Germany \\ Phone: +49-228-3894-0 \\ Fax: +49-228-3894-180 \\ E-mail: iza@iza.org
}

\begin{abstract}
Any opinions expressed here are those of the author(s) and not those of IZA. Research published in this series may include views on policy, but the institute itself takes no institutional policy positions. The IZA research network is committed to the IZA Guiding Principles of Research Integrity.

The Institute for the Study of Labor (IZA) in Bonn is a local and virtual international research center and a place of communication between science, politics and business. IZA is an independent nonprofit organization supported by Deutsche Post Foundation. The center is associated with the University of Bonn and offers a stimulating research environment through its international network, workshops and conferences, data service, project support, research visits and doctoral program. IZA engages in (i) original and internationally competitive research in all fields of labor economics, (ii) development of policy concepts, and (iii) dissemination of research results and concepts to the interested public.
\end{abstract}

IZA Discussion Papers often represent preliminary work and are circulated to encourage discussion. Citation of such a paper should account for its provisional character. A revised version may be available directly from the author. 
IZA Discussion Paper No. 9383

September 2015

\section{ABSTRACT \\ The Effect of Language on Economic Behavior: Experimental Evidence from Children's Intertemporal Choices ${ }^{\star}$}

According to Chen's (2013) linguistic-savings hypothesis, languages which grammatically separate the future and the present (like English or Italian) induce less future-oriented behavior than languages in which speakers can refer to the future by using present tense (like German). We complement Chen's approach with experimentally elicited time preference data from a bilingual city in Northern Italy. We find that German-speaking primary school children are about $46 \%$ more likely than Italian-speaking children to delay gratification in an intertemporal choice experiment. The difference remains significant in several robustness checks and when controlling for a broad range of factors, including risk attitudes, IQ or family background.

JEL Classification: C91, D03, D90

Keywords: intertemporal choice, language, children, experiment

Corresponding author:

Matthias Sutter

Department of Economics

University of Cologne

Albertus-Magnus-Platz

50923 Köln

Germany

E-mail: matthias.sutter@wiso.uni-koeln.de

\footnotetext{
* We are particularly grateful to Loukas Balafoutas, Marco Casari, Keith Chen, Simon Gächter, Uri Gneezy, Martin Kocher, David Laibson, Aldo Rustichini, Uwe Sunde, Gottfried Tappeiner and seminar participants at the Economic Science Association meetings in Cologne and Tokyo, the Royal Economic Society Meeting in London, the Max Planck Institute of Economics in Jena, and at the universities of Milan-Bocconi, Cologne, Copenhagen, Gothenburg, Innsbruck, Mainz and Notthingham for very helpful comments. We thank Rudolf Meraner from the South Tyrolean State Board of Education (Deutsches Bildungsressort Bereich Innovation und Beratung), the schools' headmasters (Gabriella Kustatscher, Maria Angela Madera, Eva Dora Oberleiter, Brigitte Öttl, Ursula Pulyer, Vally Valbonesi), the parents of the involved children for making this study possible, and the children for participation. Financial support from the Government of the autonomous province South Tyrol through grant 315/40.3 is gratefully acknowledged.
} 


\section{INTRODUCTION}

The need to make intertemporal choices is ubiquitous in human life. Investing in education (by forgoing immediate earnings from a job), saving for retirement (by giving up current consumption), or eating healthy food and exercising regularly (rather than succumbing to calory-heavy food and saving the sweat from exercising) are examples of very important intertemporal decisions with long-term consequences. Many disciplines, including economics, have studied how patience in intertemporal choices - meaning to prefer a later, but larger reward over a sooner, but smaller reward - is related to subjects' health and wealth. For instance, it has been shown that more patient adults perform better in their job and stay on their job for longer (Burks et al., 2009), have less credit card debt (Meier and Sprenger, 2010, 2012), and that they are less likely to smoke (Chabris et al., 2008). For teenagers, a positive relation between patience in intertemporal choice experiments and performance in school or a healthy lifestyle has also been documented (Castillo et al., 2011; Sutter et al., 2013). Even more impressive, long-term studies have shown that a child's degree of patience (measured in experiments or assessed by parents and teachers) is positively related to long-term outcomes in adulthood, such as higher education, higher income, better health status (by being less likely obese, drinking or smoking) or lower crime rates (Mischel et al., 1989; Moffitt et al., 2011; Golsteyn et al., 2014). Hence, patience in intertemporal choice is a very important behavioral trait of children that can make a difference for a lifetime (Mischel, 2014).

In this paper, we examine whether the language that children speak is related to how they make intertemporal choices. We can exploit an almost unique natural setting in the North Italian city of Meran with 38,000 inhabitants, $50 \%$ of which are German-speaking and 50\% Italianspeaking. Citizens of both language groups live next-door to one another, but schools are segregated by language, despite serving children from the same neighborhoods. We present an incentivized intertemporal choice-experiment that was run with $86 \%$ of all primary school kids in Meran, aged six to eleven years.

Why would language make a difference for intertemporal choice? A recent study by Chen (2013) has introduced the so-called linguistic-savings hypothesis. It states that languages which grammatically separate the future and the present induce less future-oriented behavior than languages in which speakers can refer to the future by using present tense. Italian, like English, requires grammatical inflection. In English, one could say "it will be cold tomorrow", but not "it is cold tomorrow". The former example uses the future verb tense while the latter uses the present. The former example characterizes languages that are said to have strong future-time reference (s-FTR; Thieroff, 2000). The latter example, however, sounds fine in languages, like 
German, that are said to have weak future-time reference (w-FTR). ${ }^{1}$ In English or Italian (both s-FTR), where future tense is used, the future may seem more distant when referring to future events, thus inhibiting future-oriented behavior, due to the separation of future and present in a grammatically proper use of the language. In German (w-FTR), the ability to refer to future events by using present tense may reduce the magnitude with which future events are discounted because they seem closer to the present and more certain to manifest. The grammatical difference between s-FTR and w-FTR languages may thus affect economic behavior $^{2}$, in particular decisions with intertemporal consequences.

Controlling for cultural values, Chen (2013) has found for cross-country data that citizens in countries with s-FTR have lower savings rates, less wealth and worse health conditions than citizens in countries with w-FTR languages. The same general relationship has also been confirmed for adult populations within countries that have both s-FTR and w-FTR languages. Comparing demographically similar households that only differ in their language shows also lower savings and poorer health for households with s-FTR.

While Chen's results are based on survey data on outcomes which are linked to time preferences (saving behavior, smoking habits, safer sex and obesity), we present a controlled and incentivized experiment in which we directly elicit intertemporal preferences, thus keeping the environment as identical as possible for members of two different language groups. Contrary to Chen's data analysis for adult populations, we study the relationship between language and intertemporal choices of children aged six to eleven years. Given the long-term consequences of patience (Mischel et al., 1989; Moffitt et al., 2011; Golsteyn et al., 2014; Mischel, 2014), we consider our focus on children an important extension, in particular because patience has been identified as crucial for human capital formation in adolescence (Golsteyn et al., 2014). Moreover, studying the behavior of children as young as six years of age avoids a potential concern against survey data from adult populations speaking different languages, which is that differences in savings between members from different language groups may be driven by small differences in interest rates across language groups. This is certainly not an issue in a controlled experiment. Furthermore, studying the relationship between language and time preferences in young children constitutes a particularly strong test of the linguistic-savings hypothesis because children have been exposed to their respective language for a much shorter

\footnotetext{
${ }^{1}$ See Chen (2013) for the classification of languages into s-FTR and w-FTR.

2 The notion that language structure can affect thought and behavior is commonly called the Sapir-Whorf hypothesis (Whorf, 1956). While it has waxed and waned, there is plenty of evidence that language can have an impact on thoughts and behavior (see, e.g., Boroditsky, 2001, on the (horizontal or vertical) conceptions of time of Mandarin and English speakers, Winawer et al., 2007, on color discrimination, or Danziger and Ward, 2010, on associations between ethnic groups).
} 
time. Finally, our setup of running an experiment with almost all primary school children in a relatively small city of 10 square miles total area allows studying the relationship between language and intertemporal choice in a place where children grow up next-door to one another and thus facing the same living conditions. The latter feature applies much less to the study of Chen (2013), providing a stress test to finding a relation of language and intertemporal preferences in a very narrowly confined geographical environment.

We find in our study that German-speaking children are significantly more patient in their choices than Italian-speaking children. This general pattern persists across all age groups, indicating that already at the age of six years there is a strong difference between both groups of children. This finding is replicable also with another method of eliciting intertemporal preferences, and it is robust to controlling for socio-demographic background data, IQ and risk attitudes (which are often related to intertemporal preferences; see, e.g., Frederick et al., 2002; Dohmen et al., 2010) as well as school catchment area fixed effects. Interestingly, when parents in a household speak both languages, then the child's level of patience in experimental choices is intermediate to the cases when both parents in the household speak only one language, either Italian or German. In another robustness check, we also consider different languages by including data from immigrant children, which replicates the differences between s-FTR and w-FTR languages. We also use data from a survey among citizens in Meran to show that cultural differences are an unlikely candidate for driving the language group differences in time preferences.

The outline of the paper is as follows. In the next section we give a brief account of the historical background of bilinguality in the autonomous province of South Tyrol in Italy. Section III presents the experiment procedure and the exact design. Section IV presents, first, the main results on intertemporal choice of 860 children aged 6 to 11 from monolingual households (who only speak either German or Italian), and, second, proceeds with the following robustness tests: First, we include bilingual households and children with an immigrant background (adding in total another 555 children). Second, we test for the relation of language and intertemporal preferences when the latter are elicited in a different format. Third, we check whether children from both language groups differ with respect to their risk attitudes. In section VI we discuss the results and argue that several competing explanations are unlikely to explain our findings. Finally, section VII concludes the paper. 


\section{A BRIEF ACCOUNT OF RECENT SOUTH TYROLEAN HISTORY AND OF PARTICIPANTS’ DEMOGRAPHIC CHARACTERISTICS}

Meran is the second largest city in the autonomous province of South Tyrol in the North of today's Italy. This province was part of the Austro-Hungarian Empire for centuries before it was annexed by Italy in the aftermath of World War One and became part of Italy through the treaty of Saint-Germain in 1919. Although South Tyrol had been inhabited by both German and Italian speaking citizens (and a very tiny minority of Ladin-speaking citizens) before 1919, in the interwar-period and early years after World War Two the Italian government promoted the relocation of Italians from other parts of Italy into South Tyrol, leading to an increase of the Italian-speaking population from about 5\% before 1919 to about one third in the 1960ies (Autonome Provinz Bozen, 2014). This influx of Italian-speaking citizens led to considerable tensions between both language groups that were only resolved in the early 1970ies through an autonomous statute (Alcock, 1970) for the whole province, guaranteeing equal rights and access to the public sector to citizens of both language groups, and granting the South Tyroleans considerable independence from the national government in Rome. Today, of about half a million inhabitants in South Tyrol, slightly less than 70\% report German and about 30\% report Italian as their mother tongue. While the German population has, historically speaking, deeper roots in the region, it is noteworthy that since the 1960ies there haven't been any major movements into or out of South Tyrol, meaning that the two language groups have been living side by side in almost constant fractions for half a century by now. Nevertheless, social life is fairly segregated, with different media (like newspapers or TV channels) and leisure activities (like different football clubs). Schools are also segregated, teaching either in Italian or in German. While the curricula of both types of schools are following the same national regulations and standards, so far there are no schools with bilingual teaching and with an equal representation of Italian- and German-speaking children. All over South Tyrol, the median income of Italian-speaking households has been 24,000 Euro in 2008, and for German-speaking households 26,400 Euro (Autonome Provinz Bozen, 2010).

In Meran, $50.5 \%$ of the population speaks German and $49.1 \%$ Italian (with the rest speaking Ladin). Within the city of Meran, there is almost no segregation along language lines with respect to the area of residence. Rather, citizens of both language groups live next to each other. Both groups are also predominantly catholic. As indicated above, schools teach either in German or in Italian, and in Meran there is either a large majority of Italian-speaking or of 
German-speaking children attending a particular primary school. ${ }^{3}$ Unlike for the whole province of South Tyrol, there are no official income data available for the city of Meran, contingent on language group. However, judging from the profession of parents of the children participating in our experiment, the imputed income per month does not differ significantly between parents of children in German schools (average income of fathers of 1,840 Euro; average income of mothers of 1,734 Euro) and parents of children in Italian schools (fathers: 1,832 Euro; mothers: 1,685 Euro; $p>0.1$, Mann-Whitney $U$-tests; see Appendix for the calculation of these numbers). There is a significant difference in the likelihood of being selfemployed $(23 \%$ of fathers and $11 \%$ of mothers in German schools; $12 \%$ of fathers and $5 \%$ of mothers in Italian schools; $p<0.05$ in both cases, $\chi^{2}$-tests). Parents in German schools are on average 1.2 years older than parents in Italian schools ( $p=0.06$, Mann-Whitney $U$-tests). Family structure is also similar with respect to the number of siblings that participants in our study have. In German schools, they have 1.24 siblings on average, in Italian schools 1.23 ( $p>$ 0.7, Mann-Whitney $U$-tests).

\section{THE EXPERIMENT}

\section{III.A. Procedure}

We conducted our experiment in all fourteen primary schools in Meran (South Tyrol, Italy) in April and May 2012. In Italy, primary school comprises grades 1 to 5, with children aged 6/7 years to those of 10/11 years of age. Our experiment was part of a larger research project which investigated economic decision making of primary school children. ${ }^{4}$ Before starting the project we obtained permission from the Internal Review Board of the University of Innsbruck, the South Tyrolean State Board of Education, from the headmasters of the schools and the parents of the involved children to run a series of six experimental sessions in the two academic years $2011 / 12$ and 2012/13. We obtained permission from $86 \%$ of parents of all primary school children in Meran. The experiments were run during regular school hours. Participation in each experimental session was, of course, voluntary for children, but all except a single child consented to participate.

\footnotetext{
${ }^{3}$ There are only seven (out of more than 400) children whose parents speak only German who attend an Italian school, and only 17 (out of more than 400) children with only Italian-speaking parents attending a German school.

${ }^{4}$ In Lergetporer et al. (2014) we report about an experiment on cooperation and third party punishment. In Angerer et al. (2015) we present evidence about charitable giving of primary school children (donating to needy children in the region).
} 
The experiment on intertemporal choices was run during the third occasion to visit the children in the first year of the study. Therefore, children had already experience with economic experiments (on social preferences) and receiving delayed payoffs (which was necessary for practical reasons in the previous experiments that were not related to intertemporal choice, though).

The children were fetched from the classroom and brought to a separate room where the experiment took place. The task was explained individually to each single child by one of the experimenters. All the experimenters had to memorize the experimental instructions (see Appendix) and explain the game orally (in the child's mother-tongue) to the participant. The explanation involved control questions to check for understanding and in addition all the children had to repeat the rules of the game in their own words before making their decisions. Only 13 children did not understand the task properly and their data were therefore excluded from the analysis.

The decisions of the children were incentivized with experimental tokens which could be exchanged for little presents, like candies, peanuts, stickers, marbles, balloons, wristbands, hair ties and other non-monetary rewards in our experimental shop. Each present was worth one token. The children didn't know which presents were available in the experimental shop when decisions were made. But it was clear to them that more tokens would allow them to choose more presents. In each series of experiments, we changed the available types of presents in order to avoid any potential satiation effects.

\section{III.B. Experimental design}

The experiment was run with paper and pen, and it lasted about 5 to 7 minutes. We elicited children's time preferences with the use of a simple choice list. Each child had to make a decision in three binary decision problems. Each choice problem involved a decision between receiving 2 tokens at the end of the experiment and receiving a larger number of tokens with a delay of 4 weeks. The delayed payoff was either 3 tokens, 4 tokens or 5 tokens. In order to simplify the decision problems for the children we presented each choice problem on a separate decision sheet (see a specimen in the Appendix). The caption of the decision sheets was adapted to the language of the respective child. The order of presentation of the decision sheets was varied across children. We either presented the choices in an ascending or descending order with respect to the delayed payment. The order has no effect on choices, and therefore data are pooled in the results section. 
At the end of the experiment one of the three decisions was randomly selected by the child drawing blindly one out of the three decision sheets. The decision on the drawn sheet was implemented then. If the delayed payment had been chosen, the presents were delivered to the children in a sealed envelope exactly 4 weeks after the experiment. If a child had chosen the sooner payment of 2 tokens, the child could exchange these tokens into presents immediately after the experiment.

Finally, a post-experimental questionnaire was completed in order to elicit demographic variables such as gender, age, or number of siblings. In the second year of the project, about six months after the experiment on intertemporal choices, we also measured children's IQ with a modified version of Raven's “Colored Progressive Matrices". The original test comprises 3 sets with 12 items in each set. The difficulty in each set increases with the number of the respective item. Due to time constraints we decided to use only the last 9 items from each set and therefore we excluded the first 3 items (the easiest in each set) which we expected most of the children to answer correctly. Each item consists of a geometric figure or pattern with a missing piece. The children had to find the missing piece among 6 possible items. The IQ-variable for each subject gives the number of correct answers and ranges therefore from 0 to 27 . To account for age effects in the IQ-measure, we calculate the number of correct answers relative to the average correct answers within each grade. The IQ-measure serves as a control in the regression analysis to explain subjects' intertemporal choices.

As an additional control, we measured children's risk attitudes in the same session with the IQ-measurement. Children received an initial endowment of 5 tokens and had to decide how many tokens to invest into a risky lottery (following Charness and Gneezy, 2010). The lottery yielded 2 or 0 tokens with equal probability for each token invested. Non-invested tokens were safe earnings for the child. Payments from this risk experiment were paid at the end of the experimental session. In our analysis, the number of tokens invested into the lottery will be used as a measure for children's risk-taking propensity.

Note that in the second year we could only work with children in grades 2 to 5 (who were in grades 1 to 4 in the first year). For this reason, when controlling for IQ and risk preferences below, we lose the fifth graders from the first year of the project, and thus the number of observations in the respective regressions becomes smaller when we add these controls. 


\section{RESULTS}

In this section, we focus on 860 children whose parents are either both German-speaking ( $N=420)$ or both Italian-speaking $(N=440)$ and who indicate that at home they only speak either German or Italian (see Table 1 for a breakdown into gender and grade). We present both non-parametric and regression results, controlling for a host of background variables. In the next section, we include also bilingual children and present several other robustness checks of the main result established in this section.

\section{Table 1 about here}

\section{IV.A. Non-parametric analysis}

We start with simple non-parametric tests concerning the differences between Italian- and German-speaking children. Figure 1 shows the overall relative frequency of patient choices, separated by language and for each grade. The dark bars indicate German-speaking children, and the light bars present data for Italian-speaking children. Starting already with 6- to 7-year old first graders, German-speaking children have a significantly larger likelihood of choosing the later, and larger reward than Italian-speaking children $(p<0.05$ in each grade; MannWhitney $U$-tests). From Figure 1 we also see that the relative frequency of patient choices is increasing from $1^{\text {st }}$ grade to $5^{\text {th }}$ grade in both language groups $(p<0.01$, Cuzick's Wilcoxontype tests for trend).

\section{Figures 1 to 3 about here}

Looking at the three different tasks separately, Figure 2 presents the relative frequency with which children decided to wait for 3 , respectively 4 or 5 , tokens. Overall, the figure shows that Italian-speaking children are less likely to wait for the later, but larger reward in each single task, and in each grade. While in panels "Wait for 3" and "Wait for 4" the differences are not always significant $t^{5}$, panel "Wait for 5" shows a persistent difference between both language groups ( $p<0.05$ in each grade and panel; $\chi^{2}$-tests). Panels "Wait for 4" and "Wait for 5 " show an increasing likelihood to wait for the larger reward for older children $(p<0.05$ for each language group, Cuzick's Wilcoxon-type tests for trend), while there is no such trend for "Wait for 3".

\footnotetext{
5 "Wait for 3 ": $p<0.1$ for $1^{\text {st }}$ graders; $p \leq 0.05$ for $3^{\text {rd }}$ and $4^{\text {th }}$ graders and $p>0.1$ for $2^{\text {nd }}$ and $5^{\text {th }}$ graders. "Wait for 4 ": $p>0.1$ for $2^{\text {nd }}$ graders; $p=0.1$ for $1^{\text {st }}$ graders; $p<0.05$ for $3^{\text {rd }}$ and $4^{\text {th }}$ graders; $p<0.1$ for $5^{\text {th }}$ graders; $\chi^{2}$-tests.
} 
From a child's pattern of choices in all three tasks, one can classify five different types, as shown in Figure 3. The "always patient" type waits for the larger reward in all three tasks. While this type is not very frequently observed, the rates among German-speaking children are double those among Italian-speaking children $\left(p<0.05 ; \chi^{2}\right.$-test). The type "wait for 4 and 5 " chooses the larger, but later reward when 4 or 5 tokens are available, but is impatient in the choice between 2 tokens right now and 3 tokens in four weeks. Again, this type is much more frequent among German-speaking than among Italian-speaking children ( $p<0.05 ; \chi^{2}$-test), and its frequency is increasing with age. The type "wait for 5" is only patient when the maximal stakes are available for waiting, but chooses the 2 tokens now when 3 or 4 tokens are available with a delay. This type is fairly equally distributed across the language divide (except for the first two grades, where patience is again more pronounced among German-speaking children). The "always impatient" type never waits for the larger reward, but always chooses the 2 tokens now. This type, although decreasing across age, is significantly more likely among Italianspeaking than among German-speaking children $(p<0.05$ in each grade, except for 9/10 year olds where $p<0.1 ; \chi^{2}$-tests). The share of "inconsistent" types shows no clear pattern and differences across language groups. A child's choice pattern is classified as "inconsistent" if it includes a case where the child waits for $x$ tokens in four weeks, but not for $x+1$ tokens in four weeks. ${ }^{6}$

\section{IV.B. Regression results}

The pattern that German-speaking children are significantly more patient is corroborated in a series of regressions. Table 2 presents the most basic (ordered probit) regression in column [1]. The dependent variable is constructed as the total number of patient choices (minimum of zero; maximum of three). ${ }^{7}$ Older children and German-speaking children are more patient by choosing more often the later, but larger, reward ( $p<0.01$ for each independent variable). Adding important demographic controls in columns [2] and [3] does not change the significance of language. The additional control variables add a few further insights, though. Children who are less risk averse and perform better in a non-verbal IQ-test are more patient ${ }^{8}$ (see column [2]). Controlling for household income with several proxies preserves the significance of

\footnotetext{
${ }^{6}$ The relative frequency of inconsistent choices is well in the range of what is observed in multiple choice lists for adults (see, e.g., Holt and Laury, 2002, for inconsistent choices in a multiple choice list for eliciting risk attitudes). All results presented in the paper persist if we would exclude the set of children who make time inconsistent choices.

${ }^{7}$ Tables A.1 to A.3 in the Appendix show that the same general findings (as those reported in Table 2 here) persist if we run separate regressions for each of the three tasks.

${ }^{8}$ The relation of IQ to patience matches the findings in Dohmen et al. (2010) for a representative sample of the German population.
} 
language in column [3]. We have not been able to get direct access to parents' income. Instead, we have used the following proxies. First, we have a variable capturing the number of years of education of a child's father and mother. Second, we use data on estimated income of father and mother, based on information about the parents' profession (which we do have for most children). Third, we include a proxy for the average real estate prices in the district of town where a child lives. ${ }^{9}$ Adding these proxies reduces the coefficient for the variable "German speaking" slightly, but it is still highly significant and substantial in size. Finally, adding catchment area fixed effects in order to account for unobserved heterogeneities across districts, or adding dummies for self-employment of fathers or mothers, leaves the results in Table 2 unchanged (not shown).

Table 2 about here

\section{ROBUSTNESS CHECKS AND RISK ATTITUDES}

\section{V.A. Considering children with one parent Italian-speaking and the other German-speaking}

Our main finding from the previous section is based on monolingual households. Given the strong difference in the intertemporal choice behavior of children, depending on whether they speak German or Italian, one straightforward question is what happens to the choice behavior of children from households in which both languages are spoken. Since we know the mother tongues of both the father and the mother and in which language a child speaks with the mother and the father, we can identify 203 children who speak both German and Italian at home with their parents. These children are on top of the 860 that we analyzed in section IV.

\section{Figure 4 about here}

Figure 4 presents the average relative frequency of patient choices in the monolingual (German or Italian) and the bilingual households in which children speak both Italian and German. The latter group lies almost exactly in between the two monolingual groups. Comparing the choice behavior of the 203 children from bilingual households to the other two groups, we find that they are significantly less patient than the group of only German speaking

\footnotetext{
${ }^{9}$ Please refer to the Appendix for a detailed description of how these variables were constructed.
} 
children (average relative frequency of 0.45 vs. $0.51 ; p<0.05 ; N=623$; Mann-Whitney $U$-test), but significantly more patient than only Italian speaking children (average relative frequency of 0.45 vs. $0.35 ; p<0.01 ; N=643$; Mann-Whitney $U$-test). These findings suggest that speaking at least with one parent a w-FTR-language (like German) at home is related to more patient choices in the intertemporal choice experiment. In a next step we can examine whether this holds also true if the second language spoken in the household is not Italian, but any other sFTR-language.

\section{V.B. Considering children from families in which one other language than German or Italian} is spoken

Here we consider a set of additional 91 children (on top of the 1063 analyzed so far) from families where one parent speaks either German (25) or Italian (66) with the child, but the second parent speaks a different language. ${ }^{10}$ For the 25 children with one German-speaking parent, the second language spoken in the household is a s-FTR language in all but two cases (where the second language is Indonesian, respectively Portuguese). ${ }^{11}$ The second language of 63 out of the 66 children who have one Italian-speaking parent is a s-FTR-language (meaning that both parents speak a s-FTR-language). ${ }^{12}$ We find that the average relative frequency of patient choices is 0.45 for children with one German-speaking parent, but only 0.30 for children where both parents speak a s-FTR-language (with at least one Italian-speaker). The difference is significant at $p=0.040$ (Mann-Whitney $U$-test). While in all of these 91 cases at least one parent was a native (speaking Italian or German), we can finally check also the choice behavior of children whose parents are both immigrants, speaking languages other than German or Italian. While immigrants and natives may differ in other respects (for which reason Chen, 2013, excludes immigrants in his analysis), the following is intended to provide some suggestive evidence that children from families with s-FTR-languages differ in their intertemporal choices from children in whose families a w-FTR-language is spoken.

\footnotetext{
${ }^{10}$ Languages are classified into s-FTR and w-FTR according to Chen (2013).

11 The most frequent languages alongside one German-speaking parent are Spanish (4 cases), Hungarian, Slovakian and Polish (3 each). We also have three cases where one parent speaks Portuguese (a w-FTR-language) and the other parent speaks Italian.

12 The other three children's second language is Portuguese. As for the 63 children with one parent speaking Italian and the other one another s-FTR-language, the most frequent cases are Albanian (12 cases), Spanish (8), Slovakian (6), Russian and Romanian (5 each).
} 


\section{V.C. Children from families where parents speak neither German nor Italian}

On top of the 1,154 children considered so far, we have 261 children where both parents speak a s-FTR-language which is not Italian. ${ }^{13}$ The most frequent of these languages are Albanian (95 cases), Arabic (40), Macedonian (22), Urdu (19), Bosnian/Serbian (18), Hindi (7), and Polish (6). We can compare the choice behavior of these children to the monolingual Italian-speaking children (440 children) who also belong to the s-FTR group and to the monolingual German-speaking children (420) from the w-FTR group.

The average relative frequency of patient choices is 0.37 for these 261 children with immigrant background who speak a s-FTR-language at home, which is not significantly different from the monolingual Italian-speaking children $(0.35 ; p>0.4$; Mann-Whitney $U$-test), but significantly smaller than for the German-speaking children $(0.51 ; p<0.01$; Mann-Whitney $U$-test). Hence, we find no difference in the choice behavior of children from families where only s-FTR-languages are spoken (Italian or any other s-FTR-language spoken by parents of our children's sample), yet compared to the set of monolingual German-speakers (w-FTR) there is a strong difference which mirrors the results in section IV.

\section{V.D. Replicating the results of section IV with a different method six months later}

As another robustness check addressing the experimental elicitation method, we ran a second experiment on intertemporal choices six months after the choice list task about which we have reported so far. The second experiment was conducted in the second year of the project, including children in grades 2 to 5 (who had been in grades 1 to 4 in the project's first year).

Children received an initial endowment of 5 tokens and had to decide how many tokens to consume (i.e., exchange for presents) at the day of the experiment and how many tokens to invest into the future. The investment yielded 2 tokens in four weeks for each token invested in the experiment. Thus, the number of tokens invested into the future represents a subject's patience in this design (which is similar to the convex time budget method of Andreoni and Sprenger, 2012).

Figure 5 and Table 3 about here

\footnotetext{
${ }^{13} \mathrm{We}$ only have three children in our dataset with parents speaking a w-FTR-language which is not German (in all three cases, both parents speak Chinese).
} 
Figure 5 presents the fraction of tokens invested into the future, separated by grade and language spoken. ${ }^{14}$ Again, we see a strong and significant difference between German-speaking and Italian-speaking children ( $p<0.01$ in each grade; Mann-Whitney $U$-tests). On average, German-speaking children invest 2.44 tokens into the future, but Italian-speaking children only 1.57. Hence, German-speaking children save about 55\% more of their token endowment for the future than Italian-speaking children. Table 3 confirms that the differences between both language groups remain significant when controlling for several other variables. ${ }^{15}$ That means that the elicitation method does not seem to be crucial for our main result.

\section{V.E. Is language also correlated with risk attitudes?}

The language-savings hypothesis refers to intertemporal choices, but not to choices under risk. Since intertemporal preferences and risk attitudes are often considered as related (e.g., Chabris et al., 2008; Burks et al., 2009; Dohmen et al., 2010) we were interested to see whether German- and Italian-speaking children differed also in their risk attitudes. If this was the case, we would be worried that the difference we found in intertemporal choices is mainly driven by something unrelated to the language-savings hypothesis. For this reason, we ran a simple experiment to measure risk attitudes (see Appendix for instructions).

\section{Table 4 about here}

Out of the 5 tokens of endowment in the risk experiment, German-speaking children invested on average 2.32 tokens into the lottery, and Italian-speaking children invested 2.45 tokens. The difference is not significant, neither in a simple non-parametric test $(p>0.1$; MannWhitney $U$-test), nor when running an ordered probit regression on the number of tokens invested (see the insignificant variable "German speaking" in Table 4). Hence, language is related to intertemporal choices - as the linguistic-savings hypothesis suggests - but not to risk attitudes.

\footnotetext{
${ }^{14}$ In order to keep the analysis of the second experiment on intertemporal choices as comparable as possible to the approach presented in section IV, we present in Figure 5 (and Table 3) only data for children from monolingual households $(N=666$ in total). Including children from bilingual households would not change the pattern of results emerging from Figure 5 and Table 3, however.

${ }^{15}$ It is noteworthy, that on the individual level behavior in the first experiment - with the choice list design - and the second experiment - with 5 tokens as endowment - is positively correlated. The Spearman rank order correlation between number of patient choices in the first experiment and number of tokens invested into the future in the second experiment is $0.37(p<0.01 ; N=632)$.
} 


\section{DISCUSSION}

Although we have controlled for a series of background variables in our attempt to find a relation between language and intertemporal choices, one might argue that the effects of language may capture differences in cultural values between German- and Italian-speaking citizens of Meran, such as how important it is considered to save for the future. To address this concern, we note, first, that Chen (2013) has found for his samples that controlling for such cultural values preserves the language effect as predicted by the language-savings hypothesis. Second, we have run a survey (see the Appendix for the whole set of questions) among 177 citizens of Meran in September 2013 to gain further insights into potential differences in the attitudes of Italian- and German-speaking citizens towards saving and intertemporal choices. All respondents were born in South Tyrol and currently resident in Meran. Ninety of them were Italian-speaking, and 87 German-speaking. The average age was 41 years, meaning that respondents were on average about 30 to 35 years older than children participating in the experiment. Hence, they are approximately in the age of the parents of the children that participated in our experiments (the average age of our participants' parents is 43 years). Among others, we asked respondents about which values they thought children should learn at home. The share of respondents considering "thrift" as important did not differ across languages ( $p>0.1 ; \chi^{2}$-test). We also asked respondents how important they considered "patience" or "thrift" for themselves personally, respectively for a society as a whole, again finding no differences between German- and Italian-speaking respondents $(p>0.2$ in all cases; MannWhitney $U$-tests). We consider results from the survey as an indication that the subjective importance of being patient or thrifty, and thus the cultural attitudes towards intertemporal choices, do not differ between the Italian- and German-speaking population in the city of Meran. Most importantly for our study, there is also no difference in how important thrift is considered for the education of children. This means that although the perception of the importance of these features does not differ across language groups, actual behavior of children does differ by quite a bit.

Another objection to the language-savings hypothesis might be that children learn languages with weak future-time reference differently than languages with strong future-time reference and that therefore the ability to refer to the future - and thus to make future-oriented choices - may develop differently. It seems, however, that the time path of learning languages does not differ between w-FTR and s-FTR languages (Szagun, 1978), which makes this potential explanation an unlikely candidate for our findings. 


\section{CONCLUSION}

In a controlled experiment, we have seen strong differences in the intertemporal choices of Italian-speaking and German-speaking children in a northern Italian city in which half of the inhabitants speak German, and the other half Italian. These differences persist even when we control for personal characteristics and family background, thus supporting a language-savings hypothesis that was recently developed and tested with data from adult populations by Chen (2013). Chen's hypothesis states that the Italian language - which belongs to the group of languages with strong future-time-reference (s-FTR) - induces less future-oriented behavior than the German language - which belongs to the group of languages with weak future-timereference (s-FTR). Our direct experimental test has found support for this hypothesis. Considering also families where other languages than German or Italian are spoken has provided further supportive evidence that children from families where only s-FTR-languages are spoken are more impatient than children from families where a w-FTR-language is spoken. We have found no evidence that German- and Italian-speaking children are generally different in their economic behavior, because there has been no difference across the language divide in a simple risk experiment. Also it seems that cultural values with respect to intertemporal choice are similar across adult citizens in the city of Meran.

A straightforward implication of our main finding is the question how one can contain the higher degree of impatience in speakers of s-FTR languages. This is where recent work in behavioral economics can potentially offer a starting point for future studies. Setting appropriate defaults, encouraging active decision making (by making the choice options more transparent and forcing subjects to make a choice), or providing commitment facilities has been identified as useful instruments to promote future-oriented behavior (Choi et al., 2003; Carroll et al., 2009; Beshears et al., 2011; Sutter et al., 2015). Given our findings on the relation between language and intertemporal choices, we consider it an interesting question for future research whether these instruments work equally well in languages with weak or strong futuretime reference and how they could be used to train the patience of children. Given the longterm benefits of patience (Mischel et al., 1989; Moffitt et al., 2011; Golsteyn et al., 2014; Mischel, 2014), answering these questions promises great benefits for individuals and society as a whole. 


\section{REFERENCES}

Alcock, Anthony E. 1970. The History of the South Tyrol Question. (Michael Joseph, London). Andreoni, James, and Charles Sprenger. 2012. "Estimating Time Preferences From Convex Budgets." American Economic Review, 102: 3333-56.

Angerer, Silvia, Daniela Glätzle-Rützler, Philipp Lergetporer, and Matthias Sutter. 2015.

Donations, Risk Attitudes and Time Preferences: A Study on Altruism in Primary School Children. Journal of Economic Behavior and Organization, forthcoming.

Autonome Provinz Bozen. 2010. Einkommen, Vermögen und Lebensbedingungen der Haushalte in Südtirol. Astat Schriftenreihe 164. Bozen.

Autonome Provinz Bozen. 2014. South Tyrol in Figures 2014. http://www.provinz.bz.it/astat/de/service/845.asp?830_action=300\&830_image_id=3430 71.

Beshears, John, James Choi, David Laibson, Brigitte Madrian, and Jung Sakong. 2011. "Self Control and Liquidity: How to Design a Commitment Contract." Unpublished Working Paper, Harvard University.

Boroditsky, Lera. 2001. 'Does Language Shape Thought?: Mandarin and English Speakers' Conceptions of Time.” Cognitive Psychology 43: 1-22.

Burks, Steven, Jeffrey Carpenter, Lorenz Goette, and Aldo Rustichini. 2009. "Cognitive Skills Affect Economic Preferences, Strategic Behavior, and Job Attachment." Proceedings of the National Academy of Sciences 106: 7745-50.

Carroll, Gabriel, James Choi, David Laibson, Brigitte Madrian, and Andrew Metrick. 2009. “Optimal Defaults and Active Decisions.” Quarterly Journal of Economcis 124: $1639-74$

Castillo, Marco, Paul Ferraro, Jeffrey Jordan, and Ragan Petrie. 2011. "The Today and Tomorrow of Kids: Time Preferences and Educational Outcomes of Children." Journal of Public Economics 95: 1377-85.

Chabris, Christopher F., David Laibson, Carrie L. Morris, Jonathon P. Schuldt, and Dmitry Taubinsky. 2008. “Individual Laboratory-Measured Discount Rates Predict Field Behavior." Journal of Risk and Uncertainty, 37(2-3): 237-69.

Charness, Gary, and Uri Gneezy. 2010. "Portfolio Choice and Risk Attitudes: An Experiment.” Economic Inquiry 48: 133-46.

Chen, M. Keith. 2013. "The Effect of Language on Economic Behavior: Evidence from Savings Rates, Health Behaviors, and Retirement Assets." American Economic Review 103: 690-731. 
Choi, James, David Laibson, Brigitte Madrian, and Andrew Metrick. 2003. "Optimal Defaults." American Economic Review 93: 180-5.

Danziger, Shai, and Robert Ward. 2010. “Language Changes Implicit Associations Between Ethnic Groups and Evaluation in Bilinguals.” Psychological Science 21(6): 799-800.

Dohmen, Thomas, Armin Falk, David Huffman, and Uwe Sunde. 2010. “Are Risk Aversion and Impatience Related to Cognitive Ability?" American Economic Review 100: 123860.Frederick, Shane, George Loewenstein, and Ted O'Donoghue. 2002. "Time Discounting and Time Preference: A Critical Review." Journal of Economic Literature 40: 351-401.

Golsteyn, Bart, Hans Grönqvist, and Lena Lindahl. 2014. “Adolescent Time Preferences Predict Lifetime Outcomes.” Economic Journal 124: 739-61.

Holt, Charles, and Susan Laury. 2002. "Risk Aversion and Incentive Effects." American Economic Review 92: 1644-55.

Lergetporer, Philipp, Silvia Angerer, Daniela Glätzle-Rützler, and Matthias Sutter. 2014.

"Third Party Punishment Increases Cooperation in Children Through (Misaligned) Expectations and Conditional Cooperation. Proceedings of the National Academy of Sciences 111(19): 6916-21.

Meier, Stephan, and Charles Sprenger. 2010. "Present-Biased Preferences and Credit Card Borrowing.” American Economic Journal: Applied Economics, 2(1): 193-210.

Meier, Stephan, and Charles Sprenger. 2012. "Time Discounting Predicts Creditworthiness." Psychological Science 23: 56-8.

Mischel, Walter. 2014. The Marshmallow Test. Understanding Self-Control and How to Master It. Bantam Press.

Mischel, Walter, Yuichi Shoda, and Monica L. Rodriguez. 1989. "Delay of Gratification in Children." Science, 244(4907): 933-8.

Moffitt, Terrie E., Louise Arseneault, Daniel Belsky, Nigel Dickson, Robert Hancox, HonaLee Harrington, Renate Houts, Richie Poulton, Brent Roberts, Stephen Ross, Malcolm Sears, W. Murray Thomson, Avshalom Caspi. 2011. "A Gradient of Childhood Self-Control Predicts Health, Wealth, and Public Safety.. Proceedings of the National Academy of Sciences 108: 2693-8.

Sutter, Matthias, Martin Kocher, Daniela Glätzle-Rützler, and Stefan Trautmann. 2013. "Impatience and Uncertainty: Experimental Decisions Predict Adolescents' Field Behavior." American Economic Review 103: 510-31. 
Sutter, Matthias, Levent Yilmaz, and Manuela Oberauer. 2015. "Delay of Gratification and the Role of Defaults - An Experiment with Kindergarten Children." Economics Letters, forthcoming.

Szagun, Gisela. 1978. “On the Frequency of Use of Tenses in English and German Children's Spontaneous Speech.” Child Development 49: 898-901.

Thieroff, Rolf. 2000. On the Areal Distribution of Tense-Aspect Categories in Europe. In Tense and Aspect in the Languages of Europe, edited by Östen Dahl, 309-328. Berlin: Mouton de Gruyter.

Whorf, Benjamin. 1956. Language, Thought, and Reality: Selected Writings of Benjamin Lee Whorf. Edited by John B. Carroll. Cambridge, MA, MIT Press.

Winawer, Jonathan, Nathan Witthoft, Michael C. Frank, Lisa Wu, Alex R. Wade, and Lera Boroditsky. 2007. "Russian Blues Reveal Effects of Language on Color Discrimination." Proceedings of the National Academy of Sciences 104(19): 7780-5. 


\section{Figures}

Figure 1: Relative frequency of patient choices across all three tasks ( $N=860$ overall). Error bars, mean \pm SEM

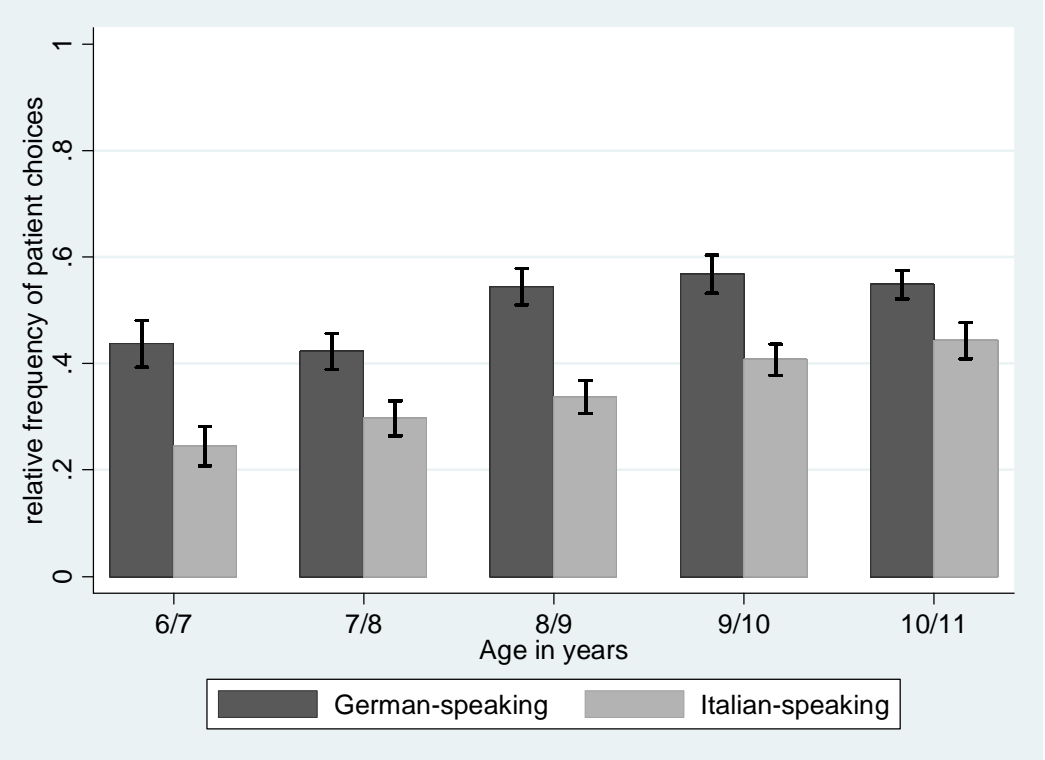


Figure 2: Relative frequency of patient choices in the three different tasks ( $N=860$ overall). Error bars, mean \pm SEM

WAIT FOR 3

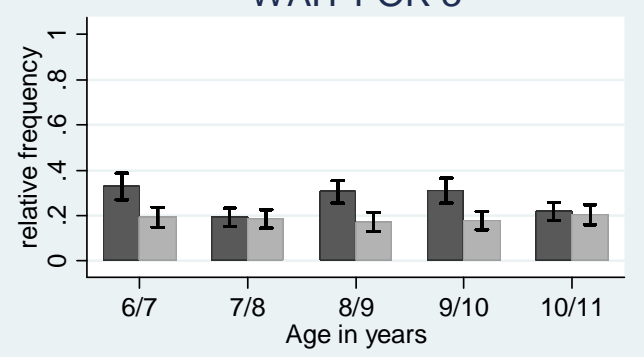

WAIT FOR 5

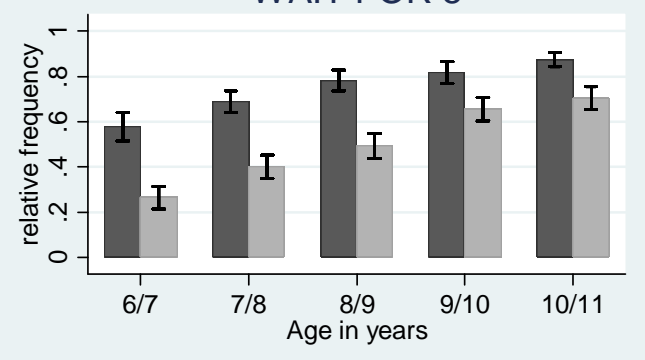

WAIT FOR 4

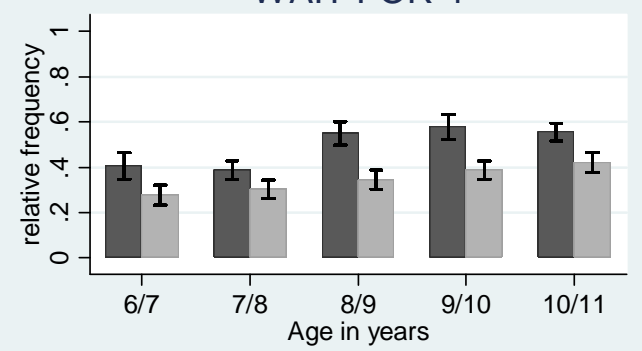

\begin{tabular}{|l|l|}
\hline German-speaking & Italian-speaking \\
\hline
\end{tabular} 
Figure 3: Relative frequency of different patterns across all three tasks ( $N=860$ overall). Error bars, mean \pm SEM
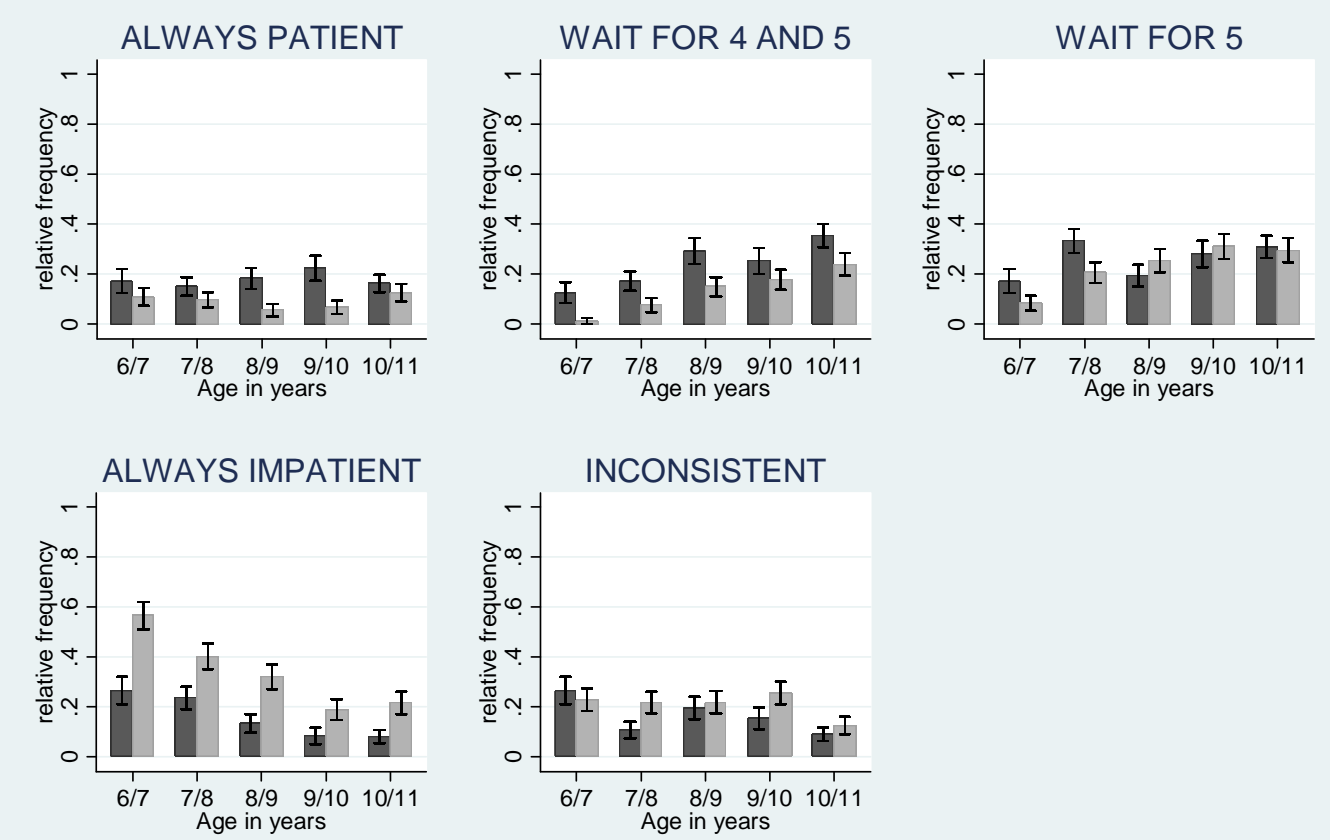

\begin{tabular}{|l|l|}
\hline German-speaking & Italian-speaking \\
\hline
\end{tabular} 
Figure 4: Relative frequency of patient choices across all three tasks, by household language ( $N=1,063$ overall, including bilingual households). Error bars, mean \pm SEM

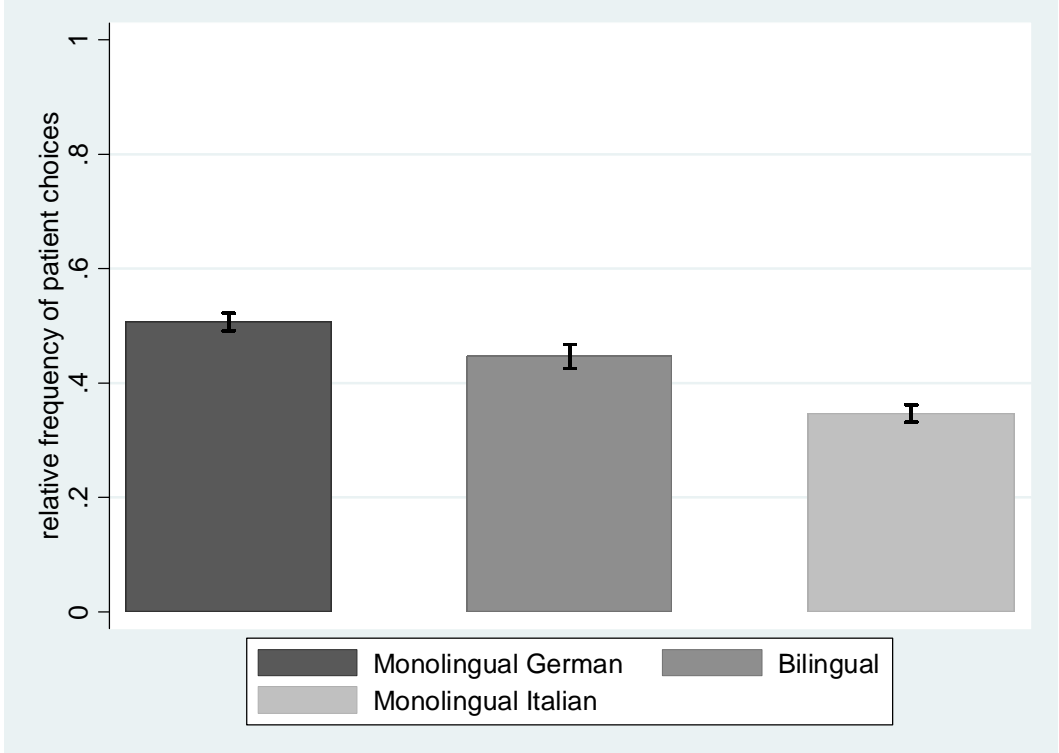

"Monolingual German" refers to children who only speak German at home and whose parents are both German-speaking $(N$ $=420$ ).

"Bilingual " refers to children who speak German and Italian with their parents $(N=203)$.

"Monolingual Italian" refers to children who only speak Italian at home and whose parents are both Italian-speaking $(N=$ 440). 
Figure 5: Second experiment on intertemporal choices. Number of tokens invested for the future $(\min =0 ; \max =5)(N=666)$. Error bars, mean \pm SEM

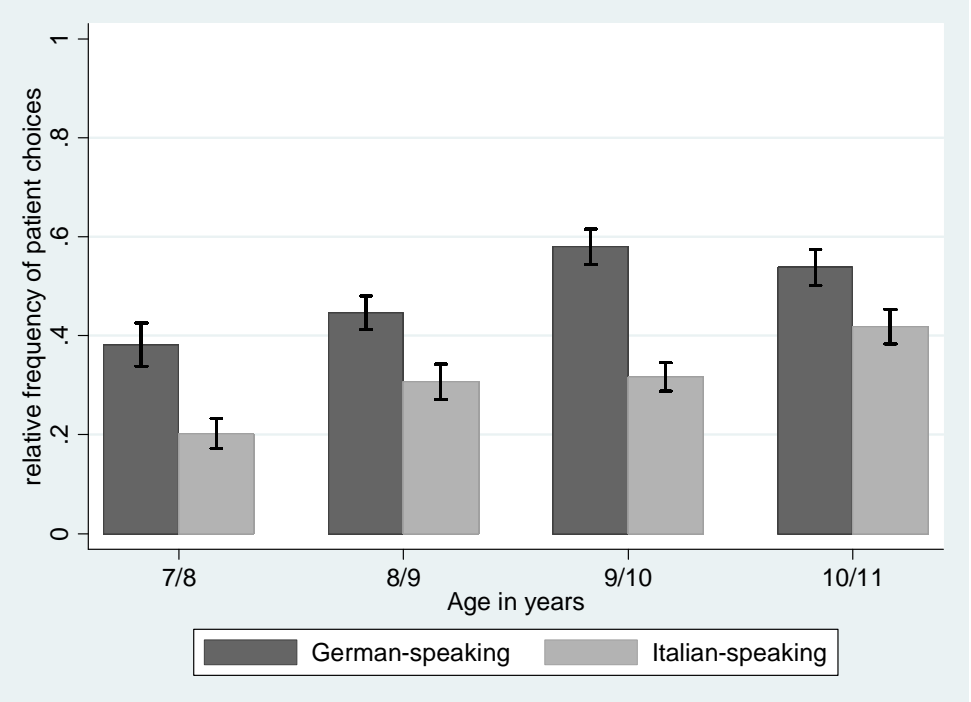




\section{Tables}

Table 1: Number of participants by age, gender, and language (including only children where at home both parents speak only one language - either German or Italian)

\begin{tabular}{lcccc}
\hline \hline & \multicolumn{2}{c}{ Italian } & \multicolumn{2}{c}{ German } \\
Age (in years) & Female & Male & Female & Male \\
\hline 6/7 years & 35 & 48 & 23 & 41 \\
$7 / 8$ years & 36 & 56 & 42 & 51 \\
8/9 years & 34 & 53 & 44 & 38 \\
9/10 years & 44 & 46 & 29 & 42 \\
$10 / 11$ years & 48 & 40 & 54 & 56 \\
\hline ALL (N=860) & $\mathbf{1 9 7}$ & $\mathbf{2 4 3}$ & $\mathbf{1 9 2}$ & $\mathbf{2 2 8}$ \\
\hline \hline
\end{tabular}


Table 2: Number of patient choices $(\min =0$; $\max =3)$. Ordered probit regressions.

\begin{tabular}{|c|c|c|c|}
\hline & (1) & (2) & (3) \\
\hline Age (in years) & $\begin{array}{c}0.151 * * * \\
(0.024)\end{array}$ & $\begin{array}{c}0.177 * * * \\
(0.037)\end{array}$ & $\begin{array}{c}0.139^{* * *} \\
(0.047)\end{array}$ \\
\hline German speaking $(=1)$ & $\begin{array}{c}0.540 * * * \\
(0.068)\end{array}$ & $\begin{array}{c}0.582 * * * \\
(0.084)\end{array}$ & $\begin{array}{c}0.480^{* * * *} \\
(0.134)\end{array}$ \\
\hline Female $(=1)$ & $\begin{array}{l}-0.134^{*} \\
(0.071)\end{array}$ & $\begin{array}{c}-0.43 \\
(0.087)\end{array}$ & $\begin{array}{l}-0.166^{*} \\
(0.098)\end{array}$ \\
\hline Number of siblings & & $\begin{array}{l}-0.001 \\
(0.046)\end{array}$ & $\begin{array}{c}0.008 \\
(0.058)\end{array}$ \\
\hline Friends other language & & $\begin{array}{c}0.017 \\
(0.111)\end{array}$ & $\begin{array}{c}0.062 \\
(0.131)\end{array}$ \\
\hline Risk-taking propensity $^{\dagger}$ & & $\begin{array}{c}0.124 * * * \\
(0.045)\end{array}$ & $\begin{array}{c}0.224 * * * \\
(0.056)\end{array}$ \\
\hline Relative $\mathrm{IQ}^{\$}$ & & $\begin{array}{c}0.791 * * * \\
(0.235)\end{array}$ & $\begin{array}{c}1.205^{* * * *} \\
(0.345)\end{array}$ \\
\hline Income father \& & & & $\begin{array}{c}-0.0003^{*} \\
(0.0002)\end{array}$ \\
\hline Income mother \& & & & $\begin{array}{l}-0.0003 \\
(0.0002)\end{array}$ \\
\hline Education father\& & & & $\begin{array}{c}0.061 \\
(0.067)\end{array}$ \\
\hline Education mother\& & & & $\begin{array}{c}0.125 \\
(0.079)\end{array}$ \\
\hline Housing prices ${ }^{\S}$ & & & $\begin{array}{c}0.0001 \\
(0.0003)\end{array}$ \\
\hline cut 1 & & & \\
\hline Constant & $\begin{array}{c}0.820 * * * \\
(0.218)\end{array}$ & $\begin{array}{c}2.123 * * * \\
(0.456)\end{array}$ & $\begin{array}{c}2.111^{* *} \\
(0.822)\end{array}$ \\
\hline cut2 & & & \\
\hline Constant & $\begin{array}{c}1.856^{* * *} \\
(0.219)\end{array}$ & $\begin{array}{c}3.175^{* * *} * \\
(0.459)\end{array}$ & $\begin{array}{c}3.224 * * * \\
(0.833)\end{array}$ \\
\hline cut3 & & & \\
\hline Constant & $\begin{array}{c}2.730 * * * \\
(0.225)\end{array}$ & $\begin{array}{c}3.998 * * * \\
(0.471)\end{array}$ & $\begin{array}{c}4.104 * * * \\
(0.845)\end{array}$ \\
\hline \# Observations & 860 & 636 & 460 \\
\hline
\end{tabular}

Notes. $* * *, * *, *$ denote significance at the $1 \%, 5 \%, 10 \%$ level, robust standard errors in parentheses. Clustered on class level.

\# This variable is equal to one if the child has at least one friend who speaks also the language of the other language group (e.g., a German-speaking child having an Italian-speaking friend; or vice versa).

$\dagger$ Number of tokens invested in risk experiment $(\min =0 ; \max =5)$. The risk taking experiment was run in the second year, in which we only worked with children in grades 2 to 5 (i.e., those children in grades 1 to 4 in the first year). Children in grade 5 in the first year left primary school and entered middle school (grades 6-8 in Italy) in the second year of our project. Hence, the number of observations when including risk attitudes is smaller than the sample that we had in the first year of the project.

$\$$ The IQ was measured relative to the respective grade (values above 1 indicate above average IQ in the respective grade; values below 1 indicate below average IQ).

\& For a detailed description of these variables see the notes on "Parents" estimated income and education" below. We did not get information about parents' professions for all children. Hence, the sample size is smaller when this variable is included as independent variable.

$\S$ For a detailed description of this variable see the notes "Proxy for housing prices (market/rental prices)" below. 
Table 3: Second experiment on intertemporal choices (October 2012). Number of tokens invested for the future $(\min =0 ; \max =5)$. Ordered probit regressions.

\begin{tabular}{|c|c|c|c|}
\hline & $(1)$ & $(2)$ & (3) \\
\hline Age (in years) & $\begin{array}{c}0.197 * * * \\
(0.035)\end{array}$ & $\begin{array}{c}0.222 * * * \\
(0.035)\end{array}$ & $\begin{array}{c}0.247 * * * \\
(0.047)\end{array}$ \\
\hline German speaking $(=1)$ & $\begin{array}{c}0.602 * * * \\
(0.077)\end{array}$ & $\begin{array}{c}0.559 * * * \\
(0.077)\end{array}$ & $\begin{array}{c}0.584^{* * * *} \\
(0.114)\end{array}$ \\
\hline Female $(=1)$ & $\begin{array}{l}-0.023 \\
(0.084)\end{array}$ & $\begin{array}{l}-0.034 \\
(0.085)\end{array}$ & $\begin{array}{l}-0.036 \\
(0.113)\end{array}$ \\
\hline Number of siblings & & $\begin{array}{c}0.011 \\
(0.043)\end{array}$ & $\begin{array}{c}0.061 \\
(0.052)\end{array}$ \\
\hline Friends other language $^{\#}$ & & $\begin{array}{l}-0.059 \\
(0.095)\end{array}$ & $\begin{array}{c}-0.027 \\
(0.102)\end{array}$ \\
\hline Risk-taking propensity $^{\dagger}$ & & $\begin{array}{c}0.083 * * \\
(0.041)\end{array}$ & $\begin{array}{c}0.101 * * \\
(0.050)\end{array}$ \\
\hline Relative IQ $\$$ & & $\begin{array}{c}1.138 * * * \\
(0.241)\end{array}$ & $\begin{array}{c}1.067 * * * \\
(0.315)\end{array}$ \\
\hline Income father \& & & & $\begin{array}{l}5.63 \mathrm{e}-06 \\
(0.0002)\end{array}$ \\
\hline Income mother \& & & & $\begin{array}{c}-0.0002 \\
(0.0002)\end{array}$ \\
\hline Education father\& & & & $\begin{array}{c}-0.025 \\
(0.066)\end{array}$ \\
\hline Education mother\& & & & $\begin{array}{c}0.177 * * \\
(0.074)\end{array}$ \\
\hline Housing prices ${ }^{\S}$ & & & $\begin{array}{l}9.69 \mathrm{e}-05 \\
(0.0002)\end{array}$ \\
\hline cut1 & & & \\
\hline Constant & $\begin{array}{c}1.323 * * * \\
(0.329)\end{array}$ & $\begin{array}{c}2.831 * * * \\
(0.385)\end{array}$ & $\begin{array}{c}3.408 * * * \\
(0.755)\end{array}$ \\
\hline cut2 & & & \\
\hline Constant & $\begin{array}{c}1.875 * * * \\
(0.332)\end{array}$ & $\begin{array}{c}3.389 * * * \\
(0.392)\end{array}$ & $\begin{array}{c}3.942 * * * \\
(0.765)\end{array}$ \\
\hline cut3 & & & \\
\hline Constant & $\begin{array}{c}2.484 * * * \\
(0.342)\end{array}$ & $\begin{array}{c}4.028 * * * \\
(0.396)\end{array}$ & $\begin{array}{c}4.590 * * * \\
(0.755)\end{array}$ \\
\hline cut4 & & & \\
\hline Constant & $\begin{array}{c}2.960 * * * \\
(0.344)\end{array}$ & $\begin{array}{c}4.536^{* * *} \\
(0.397)\end{array}$ & $\begin{array}{c}5.161 * * * \\
(0.765)\end{array}$ \\
\hline cut5 & & & \\
\hline Constant & $\begin{array}{c}3.178 * * * \\
(0.346)\end{array}$ & $\begin{array}{c}4.782 * * * \\
(0.396)\end{array}$ & $\begin{array}{c}5.404 * * * \\
(0.774)\end{array}$ \\
\hline \# Observations & 666 & 622 & 452 \\
\hline
\end{tabular}

Notes. $* * *, * * *$ denote significance at the $1 \%, 5 \%, 10 \%$ level, robust standard errors in parentheses. Clustered on class level.

\# This variable is equal to one if the child has at least one friend who speaks also the language of the other language group (e.g., a German-speaking child having an Italian-speaking friend; or vice versa).

$\dagger$ Number of tokens invested in risk experiment $(\min =0 ; \max =5)$. The risk taking experiment was run in the second year, in which we only worked with children in grades 2 to 5 (i.e., those children in grades 1 to 4 in the first year). Children in grade 5 in the first year left primary school and entered middle school (grades 6-8 in Italy) in the second year of our project. Hence, 
the number of observations when including risk attitudes is smaller than the sample that we had in the first year of the project.

${ }^{\$}$ The IQ was measured relative to the respective grade.

\& For a detailed description of these variables see the notes on "Parents' estimated income and education" in the Appendix.

We did not get information about parents' professions for all children. Hence, the sample size is smaller when this variable is included as independent variable.

$\S$ For a detailed description of this variable see the notes "Proxy for housing prices (market/rental prices)" in the Appendix. 
Table 4: Risk taking experiment (October 2012). Number of tokens invested in the risky gamble $(\min =0 ; \max =5)$. Ordered probit regressions.

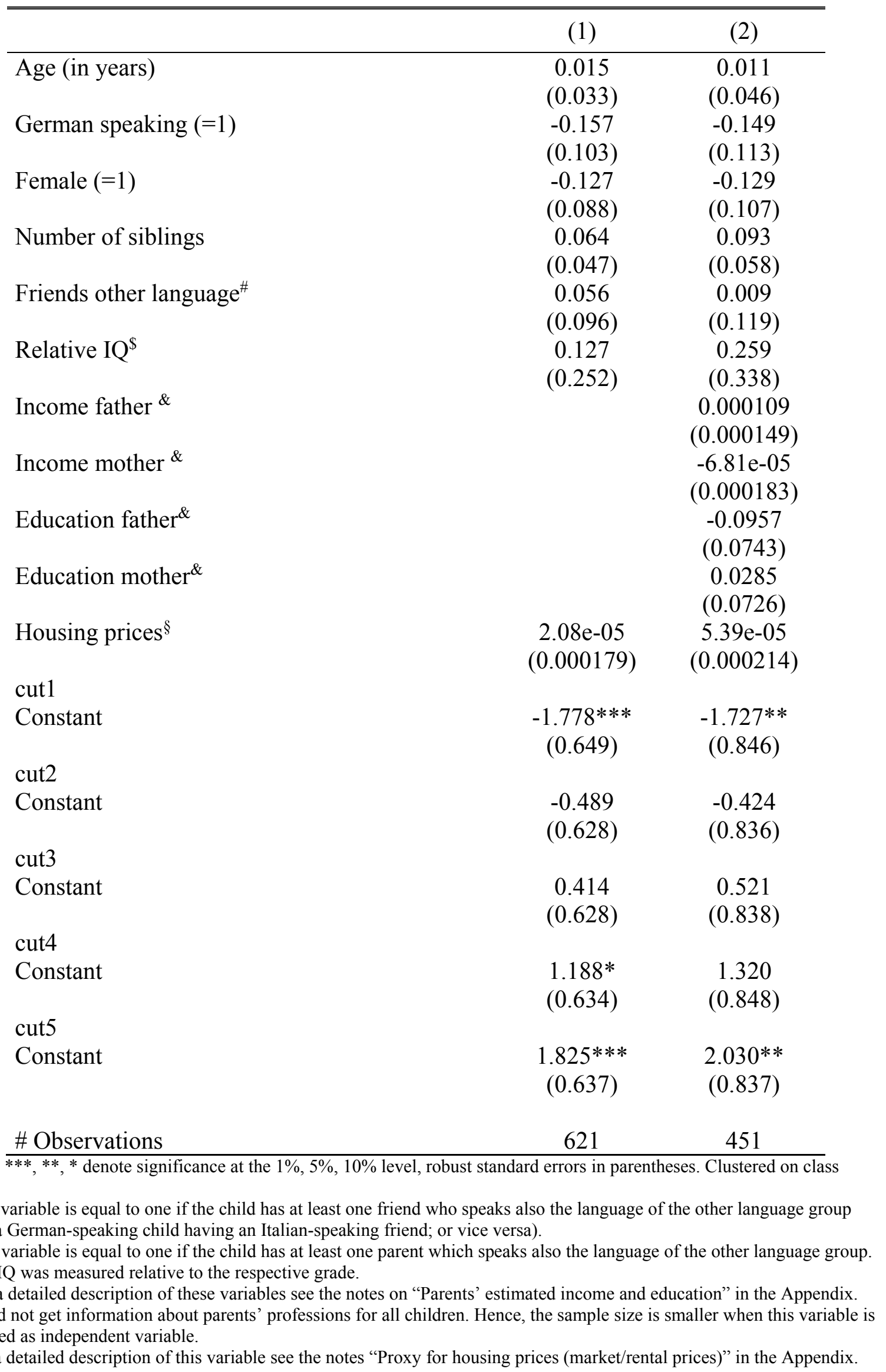




\section{Appendix - For Online Publication}

\section{Supplementary tables}

Table A.1: Probit regression for "Wait for 3 " (dependent variable = 1 if child waits for 3 tokens in four weeks).

(1)

Wait for 3
(2)

Wait for 3
(3)

Wait for 3

\begin{tabular}{|c|c|c|c|}
\hline Age (in years) & $\begin{array}{c}0.007 \\
(0.027)\end{array}$ & $\begin{array}{c}0.014 \\
(0.042)\end{array}$ & $\begin{array}{l}-0.005 \\
(0.053)\end{array}$ \\
\hline German speaking $(=1)$ & $\begin{array}{c}0.255 * * * \\
(0.091)\end{array}$ & $\begin{array}{c}0.332 * * * \\
(0.108)\end{array}$ & $\begin{array}{c}0.203 \\
(0.185)\end{array}$ \\
\hline Female $(=1)$ & $\begin{array}{l}-0.128 \\
(0.098)\end{array}$ & $\begin{array}{l}-0.123 \\
(0.121)\end{array}$ & $\begin{array}{l}-0.206 \\
(0.141)\end{array}$ \\
\hline Number of siblings & & $\begin{array}{c}0.023 \\
(0.055)\end{array}$ & $\begin{array}{c}0.035 \\
(0.071)\end{array}$ \\
\hline Friends other language $\mathrm{e}^{\#}$ & & $\begin{array}{c}0.113 \\
(0.133)\end{array}$ & $\begin{array}{c}0.117 \\
(0.161)\end{array}$ \\
\hline Risk-taking propensity $^{\dagger}$ & & $\begin{array}{l}0.094 * \\
(0.051)\end{array}$ & $\begin{array}{c}0.145^{* *} \\
(0.068)\end{array}$ \\
\hline Relative $\mathrm{IQ}^{\$}$ & & $\begin{array}{l}-0.088 \\
(0.283)\end{array}$ & $\begin{array}{c}0.274 \\
(0.431)\end{array}$ \\
\hline Income father \& & & & $\begin{array}{l}-0.0004 \\
(0.0002)\end{array}$ \\
\hline Income mother ${ }^{\&}$ & & & $\begin{array}{l}-0.0004 \\
(0.0003)\end{array}$ \\
\hline Education father\& & & & $\begin{array}{c}0.081 \\
(0.088)\end{array}$ \\
\hline Education mother\& & & & $\begin{array}{c}0.170 \\
(0.105)\end{array}$ \\
\hline Housing prices ${ }^{\S}$ & & & $\begin{array}{c}0.00005 \\
(0.0003)\end{array}$ \\
\hline Constant & $\begin{array}{c}-0.894 * * * \\
(0.256)\end{array}$ & $\begin{array}{c}-1.171^{* *} \\
(0.485)\end{array}$ & $\begin{array}{l}-0.773 \\
(1.062)\end{array}$ \\
\hline \# Observations & 860 & 636 & 460 \\
\hline \multicolumn{4}{|c|}{$\begin{array}{l}\text { Notes. }{ }^{* * *},{ }^{* *},{ }^{*} \text { denote significance at the } 1 \%, 5 \%, 10 \% \text { level, robust standard errors in parentheses. Clustered on class } \\
\text { level. } \\
\# \text { This variable is equal to one if the child has at least one friend who speaks also the language of the other language group } \\
\text { (e.g., a German-speaking child having an Italian-speaking friend; or vice versa). } \\
\text { † Number of tokens invested in risk experiment (min }=0 \text {; max }=5 \text { ). The risk taking experiment was run in the second year, in } \\
\text { which we only worked with children in grades } 2 \text { to } 5 \text { (i.e., those children in grades } 1 \text { to } 4 \text { in the first year). Children in grade } 5 \\
\text { in the first year left primary school and entered middle school (grades } 6-8 \text { in Italy) in the second year of our project. Hence, } \\
\text { the number of observations when including risk attitudes is smaller than the sample that we had in the first year of the } \\
\text { project. } \\
\text { \$ The IQ was measured relative to the respective grade. } \\
\text { \& For a detailed description of these variables see the notes on "Parents' estimated income and education" below. We did not } \\
\text { get information about parents' professions for all children. Hence, the sample size is smaller when this variable is included as } \\
\text { independent variable. } \\
\text { \$ For a detailed description of this variable see the notes "Proxy for housing prices (market/rental prices)" below. }\end{array}$} \\
\hline
\end{tabular}


Table A.2: Probit regression for "Wait for 4" (dependent variable = 1 if child waits for 4 tokens in four weeks).

(1)

Wait for 4

Age (in years)

German speaking $(=1)$

Female (=1)

Number of siblings

Friends other language ${ }^{\#}$

Risk-taking propensity ${ }^{\dagger}$

Relative IQ $\$$

Income father \&

Income mother \&

Education father ${ }^{\&}$

Education mother\&

Housing prices ${ }^{\S}$

Constant
$0.110 * * *$

(0.025)

$0.381 * * *$

(0.080)

$-0.067$

(0.090)
(2)

Wait for 4

$0.127 * * *$

(0.039)

$0.389 * * *$

(0.094)

$-0.013$

(0.102)

$-0.026$

(0.053)

$-0.014$

(0.119)

$0.127 * * *$

(0.041)

$0.645 * *$

(0.260)
(3)

Wait for 4

0.058

(0.046)

$0.345^{* *}$

$(0.144)$

$-0.0002$

(0.113)

$-0.099$

$(0.075)$

$-0.034$

$(0.140)$

$0.214 * * *$

$(0.050)$

$0.783 * *$

(0.331)

$-0.0003$

$(0.0002)$

0.00006

(0.0003)

0.109

(0.077)

0.024

$(0.083)$

$-0.00003$

(0.0003)

$-1.835^{*}$

(0.941)

Observations

$-1.339 * * *$

(0.227)
$-2.409 * * *$

(0.474)

460

\footnotetext{
Notes. $* * *, * *, *$ denote significance at the $1 \%, 5 \%, 10 \%$ level, robust standard errors in parentheses. Clustered on class level.

\# This variable is equal to one if the child has at least one friend who speaks also the language of the other language group (e.g., a German-speaking child having an Italian-speaking friend; or vice versa).

$\dagger$ Number of tokens invested in risk experiment $(\min =0 ; \max =5)$. The risk taking experiment was run in the second year, in which we only worked with children in grades 2 to 5 (i.e., those children in grades 1 to 4 in the first year). Children in grade 5 in the first year left primary school and entered middle school (grades 6-8 in Italy) in the second year of our project. Hence, the number of observations when including risk attitudes is smaller than the sample that we had in the first year of the project.

$\$$ The IQ was measured relative to the respective grade.

\& For a detailed description of these variables see the notes on "Parents' estimated income and education" below. We did not get information about parents' professions for all children. Hence, the sample size is smaller when this variable is included as independent variable.

$\S$ For a detailed description of this variable see the notes "Proxy for housing prices (market/rental prices)" below.
} 
Table A.3: Probit regression for "Wait for 5" (dependent variable = 1 if child waits for 5 tokens in four weeks).

(1)

Wait for 5

Age (in years)

$0.240 * * *$

(0.034)

German speaking $(=1)$

$0.713 * * *$

(0.093)

$-0.163^{*}$

(0.090)

Number of siblings

Friends other language

Risk-taking propensity ${ }^{\dagger}$

Relative IQ $\$$

Income father \&

Income mother \&

Education father ${ }^{\&}$

Education mother ${ }^{\&}$

Housing prices ${ }^{\S}$

Constant
(2)

Wait for 5

$0.266^{* * *}$

(0.050)

$0.727 * * *$

(0.114)

$-0.241 * *$

(0.109)

0.005

$(0.063)$

$-0.073$

$(0.131)$

0.078

(0.048)

$1.207 * * *$

$(0.254)$

(3)

Wait for 5

$0.258 * * *$

(0.059)

$0.642 * * *$

(0.163)

$-0.242^{*}$

(0.127)

0.081

(0.087)

0.051

(0.156)

$0.168 * * *$

(0.064)

$1.734 * * *$

(0.357)

$-0.00009$

(0.0002)

$-0.0005^{*}$

(0.0003)

$-0.033$

(0.085)

0.150

(0.093)

0.0002

(0.0003)

$-4.180 * * *$

(1.042)

Observations

Notes. ${ }^{* * *},{ }^{* *}, *$ denote significance at the $1 \%, 5 \%, 10 \%$ level, robust standard errors in parentheses. Clustered on class level.

\# This variable is equal to one if the child has at least one friend who speaks also the language of the other language group (e.g., a German-speaking child having an Italian-speaking friend; or vice versa).

$\dagger$ Number of tokens invested in risk experiment $(\min =0$; $\max =5)$. The risk taking experiment was run in the second year, in which we only worked with children in grades 2 to 5 (i.e., those children in grades 1 to 4 in the first year). Children in grade 5 in the first year left primary school and entered middle school (grades 6-8 in Italy) in the second year of our project. Hence, the number of observations when including risk attitudes is smaller than the sample that we had in the first year of the project.

$\$$ The IQ was measured relative to the respective grade.

\& For a detailed description of these variables see the notes on "Parents' estimated income and education" below. We did not get information about parents' professions for all children. Hence, the sample size is smaller when this variable is included as independent variable.

$\S$ For a detailed description of this variable see the notes "Proxy for housing prices (market/rental prices)" below. 


\section{Notes on estimated income and education of parents}

\section{Estimated income}

In order to get a measure for income we asked the children to state their parent's profession as precisely as possible. The children's answers were categorized with the use of the Public Employment Service Austria (AMS). They provide information on the average gross starting salary per month of almost 1,800 different types of professions. If a child could only give information on the company the parent works at, we used the most common profession within the same company. We used the Austrian Public Employment Service (AMS) classification because the information provided there on different types of professions is much more detailed than the information provided by the census bureau in South Tyrol (ASTAT). However, the average gross starting salary provided by both the AMS and the ASTAT have a highly significant positive correlation. Note that we did not get information about parents' professions for all children participating in our experiment.

\section{Education}

In addition to the average gross starting salary the Public Employment Service Austria (AMS) provides information on the minimum level of education necessary to pursue a particular profession (see http://www.berufslexikon.at/):

1. Other occupations ("Sonstige Berufe"):

This form of education is appropriate for subjects who have already completed another education (apprenticeship or high school degree) but want to start a new profession or for subjects who want to pursue an occupation where no other form of education exists.

2. Apprenticeship ("Lehre"):

Prerequisite: graduation from 9 years compulsory school (at age 15) and holding of an apprenticeship position. The duration of the latter varies between 2 and 4 years depending on the type of profession.

3. Middle/High school ("Schule"):

Prerequisite: graduation from 8 years compulsory school (at age 14); plus 4-5 years of middle and high school with a school leaving examination (which qualifies students for entering higher education).

4. University (,Universität, Fachhochschule, Pädagogische Hochschule“):

Prerequisite: higher education entrance qualification. Degrees: Bachelor, Master and Doctorate. 


\section{Notes on the proxy for housing prices (market/rental prices)}

Based on data from "Agenzia Entrate - OMI" Meran is structured into 9 zones (see http://wwwt.agenziaentrate.gov.it/servizi/Consultazione/ricerca.php?). Each zone is assigned a minimal and maximal market respectively rental price for (i) habitations with normal conservation status and (ii) habitations with excellent habitation status. The market price is given in Euros per square meter and the rental price is given in Euros per square meter and per month. We decided to use the prices for habitations with normal conservation status because it is the most common status for all zones according to "Agenzie Entrate - OMI". In order to obtain a single measure for market and rental housing prices we calculated the average of the respective minimal and maximal value. Table A.4 shows the average market and rental price for normal habitations in each zone.

Table A.4: Average market and rental prices in different zones of Meran

\begin{tabular}{|c|c|c|c|}
\hline Zone & Description & $\begin{array}{l}\text { Average market } \\
\text { price (in } € / m^{2} \text { ) }\end{array}$ & $\begin{array}{l}\text { Average rental price } \\
\text { (in } € / \mathrm{m}^{2} / \text { month) }\end{array}$ \\
\hline $\mathrm{B} 1$ & $\begin{array}{l}\text { Historical center and area around } \\
\text { thermal bath }\end{array}$ & 2,250 & 7.05 \\
\hline $\mathrm{B} 2$ & $\begin{array}{l}\text { Historical center and area around } \\
\text { arcades and dome }\end{array}$ & 2,425 & 7.10 \\
\hline $\mathrm{C} 1$ & $\begin{array}{l}\text { Residential area of "Obermais" and } \\
\text { "San Zeno" }\end{array}$ & 2,875 & 9.05 \\
\hline $\mathrm{C} 2$ & $\begin{array}{l}\text { Residential area: Via Verdi, Via Wolf, } \\
\text { area around hospital and "Gratsch" }\end{array}$ & 2,700 & 8.50 \\
\hline $\mathrm{C} 3$ & $\begin{array}{l}\text { Residential area between Via Roma, } \\
\text { Via Maia and Via Brennero }\end{array}$ & 2,125 & 6.70 \\
\hline $\mathrm{C} 4$ & $\begin{array}{l}\text { Area around the main station, Via } \\
\text { Tessa, Via Petrarca and "Untermais" }\end{array}$ & 2,325 & 7.30 \\
\hline D1 & $\begin{array}{l}\text { Residential area of "Obermais", area } \\
\text { around Castel Planta North and South, } \\
\text { Via Scena until Via Hagen Fink }\end{array}$ & 2,875 & 9.05 \\
\hline D3 & $\begin{array}{l}\text { Residential area in the neighborhood of } \\
\text { the main station, the horse race track; } \\
\text { "Untermais" and "Sinich" }\end{array}$ & 2,125 & 6.70 \\
\hline R1 & Agricultural area & 1,925 & 6.05 \\
\hline
\end{tabular}


To assign a specific housing price (market and rental) to each child we asked the school administrations for the catchment area of their school. Since we did not obtain data on the individual level (home addresses) we assigned the housing prices to the children on the schoollevel. Based on the catchment area of a school we calculated the average market and rental price of a school's catchment area and assigned these prices to all the children from that school. For two schools ("San Nicolò" and "Oswald von Wolkenstein GT") the catchment area is the whole town (except agricultural areas) for which reason we take an average across all zones. Table A.5 shows the corresponding market and rental housing prices for each school.

Table A.5: Average housing prices assigned to children from different schools, depending on the school's catchment area

\begin{tabular}{|c|c|c|c|}
\hline School & $\begin{array}{l}\text { Main zones where } \\
\text { children come from }\end{array}$ & $\begin{array}{l}\text { Average market } \\
\text { price }\left(\text { in } € / m^{2}\right)\end{array}$ & $\begin{array}{l}\text { Average rental } \\
\text { price (in } \\
€ / m^{2} / \text { month) }\end{array}$ \\
\hline Gilm & $\mathrm{C} 1 / \mathrm{D} 1$ & 2,875 & 9.05 \\
\hline Karl Erckert & C1/D1 & 2,875 & 9.05 \\
\hline Sinich & D3 & 2,125 & 6.70 \\
\hline Albert Schweitzer & $\mathrm{B} 1 / \mathrm{B} 2 / \mathrm{C} 2 / \mathrm{C} 4$ & 2,425 & 7.48 \\
\hline Franz Tappeiner & $\mathrm{B} 2 / \mathrm{C} 2$ & 2,562 & 7.80 \\
\hline $\begin{array}{l}\text { Oswald v. Wolkenstein } \\
\text { GT }\end{array}$ & $\begin{array}{l}\text { All zones (R1 } \\
\text { excluded) }\end{array}$ & 2,462 & 7.68 \\
\hline $\begin{array}{l}\text { Oswald v. Wolkenstein } \\
\text { Regel }\end{array}$ & $\mathrm{C} 3 / \mathrm{C} 4$ & 2,225 & 7.00 \\
\hline De Amicis & $\mathrm{C} 1 / \mathrm{D} 1$ & 2,875 & 9.05 \\
\hline Leonardo da Vinci & $\mathrm{B} 1 / \mathrm{B} 2$ & 2,337 & 7.07 \\
\hline San Nicolò & $\begin{array}{l}\text { All zones (R1 } \\
\text { excluded) }\end{array}$ & 2,462 & 7.68 \\
\hline Giovanni Pascoli & $\mathrm{C} 3$ & 2,125 & 6.70 \\
\hline Galileo Galilei TP & D3 & 2,125 & 6.70 \\
\hline Galileo Galilei TN & $\mathrm{C} 4$ & 2,325 & 7.30 \\
\hline Giovanni XXIII & D3 & 2,125 & 6.70 \\
\hline
\end{tabular}




\section{Experimental instructions (translated from German/Italian)}

Note: Italic font is used for the instructions to the experimenter.

\section{Experimental instructions “Intertemporal choices” (April/May 2012)}

Register the order of explanation (blue first or green first) in the computer.

Good morning. My name is ... Today I prepared a game for you. In this game you can earn tokens. With these tokens you can buy some presents in our shop. Each present costs 1 token. You can choose your favorite present in our shop and you will get as many pieces of this present as the number of tokens you earned in this game. The game consists of 3 parts. The blue part, the yellow part and the green part (when mentioning the parts please point at the respective decision sheets).

The game works as follows:

In the blue part you have to decide whether you prefer receiving 2 tokens (please point at the tokens on the decision sheet) immediately, in this case please tick THIS box (point at the respective box), or whether you prefer receiving 3 tokens in 4 weeks, in that case please tick THAT box (point at the respective box). If you want to receive 2 pieces of your favorite present, you will get the presents immediately after the game. If you rather want to wait, you will get three pieces of your favorite presents in 4 weeks. This is the blue part. Could you please repeat the rules of the game? (If the child is unable to repeat, please explain the game again; the child has to be able to repeat the correct meaning of the game autonomously)

The yellow part is very similar to the blue part. Here you see the decision sheet for the yellow part. Again, 2 tokens on the left-hand side, but now 4 tokens on the right-hand side. What do you think will happen if you tick THIS box? (please point at the box with the immediate reward) What do you think will happen if you tick THAT box? (please point at the box with the delayed reward of four tokens; the child has to answer the questions correctly, otherwise the experimenter has to repeat the explanation).

The green part is very similar to the blue and yellow part. Here you see the decision sheet for the yellow part. Again, 2 tokens on the left-hand side, but now 5 tokens on the right-hand side. What do you think will happen if you tick THIS box? (please point at the box with the immediate reward) What do you think will happen if you tick THAT box? (please point at the box with the delayed reward of five tokens; the child has to answer the questions correctly, otherwise the experimenter has to repeat the explanation).

It is important to note that at the end only one of the three parts counts. That means that you will receive the tokens for one of the three parts only. After your decisions I will mingle the 
three decision sheets under the table (please demonstrate; Attention: you have to handle the sheets such that the child is not able to see the color of the respective sheet! You need to cover the three parts with an additional large-format sheet when placing the sheets on the table for drawing) and then you can draw one of the three parts. (In what follows, adapt the explanation to the order in which you draw the sheets:) If you draw the blue part (demonstrate the drawing of the first sheet), only the blue part counts and you will receive the tokens for this part only. The other two parts do not count in this case. If you, for example, ticked THIS box (please point at the box with the immediate reward), what happens? If you, for example, ticked THAT box (please point at the box with the delayed reward), what happens (child must answer both questions correctly; IMPORTANT: give both examples!)? If you however draw the yellow part (demonstrate the drawing of the second sheet), only the yellow part counts and you will receive the tokens for the yellow part only. The other two parts do not count in this case. If you draw the green part (demonstrate the drawing of the third sheet), only the green part counts and you will receive the tokens for the green part only. The other two parts do not count in this case. However, you need to make a decision for each of the three parts because you don't know yet which part will be drawn at the end of the game. Could you please repeat the last part? Will you receive the tokens for all three parts? Do you need to make a decision for each of the three parts? (If the child answers incorrectly the experimenter has to repeat the explanation of this part)

Please take your decision for each of the three parts now (place the decision sheets side by side on the table; the child should fill out the decision sheets from left to right). Start with this part (point at the first decision sheet (blue or green, depending on the order of explanation)) and continue with this part (point at the second decision sheet) and finally make your decision in this part (point at the third decision sheet). Take as much time as you need. In the meantime I will turn around so that I don't disturb you. Just call me when you are done. 
Decision sheets for the intertemporal choice experiment (translated from Italian, respectively German)
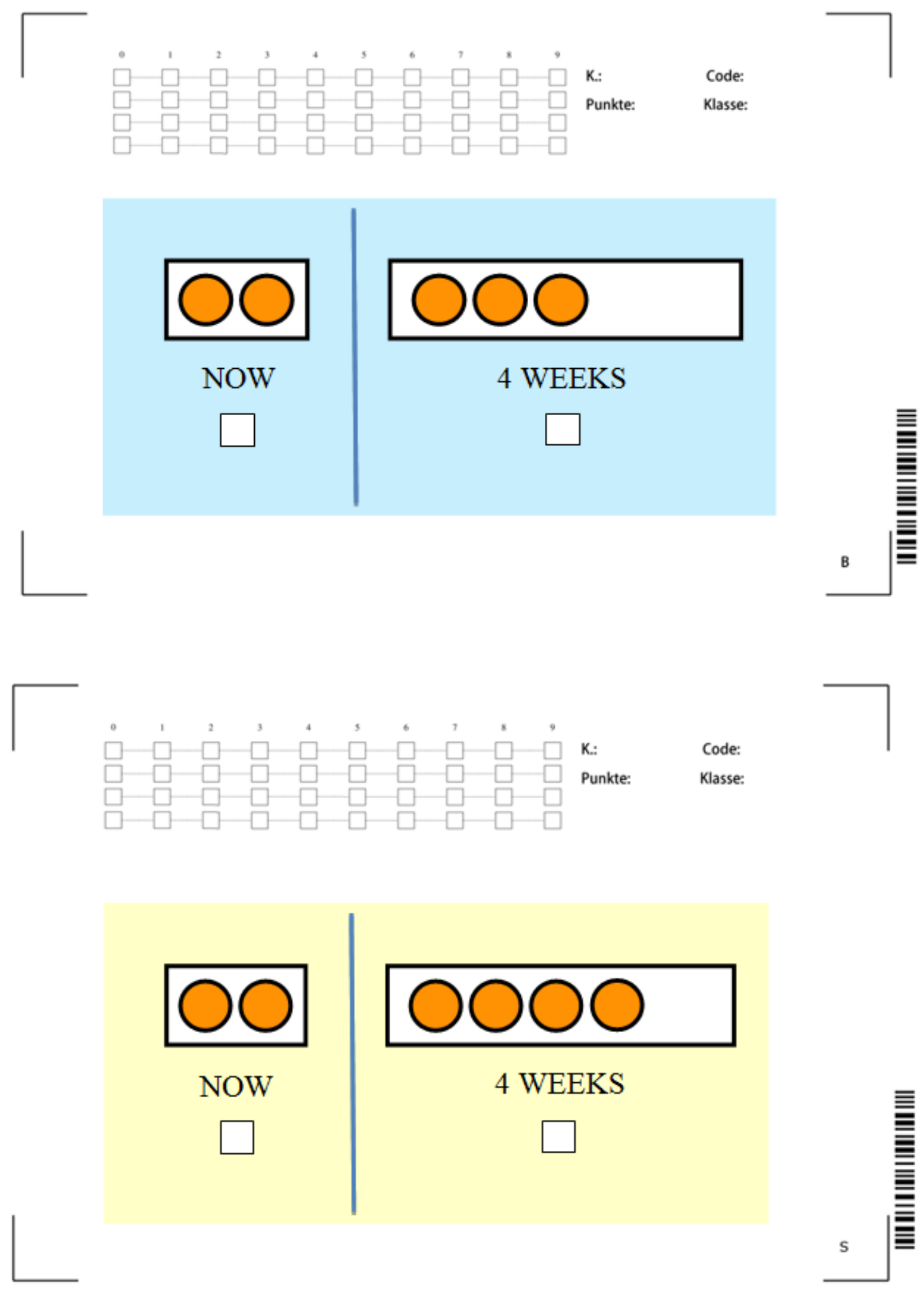


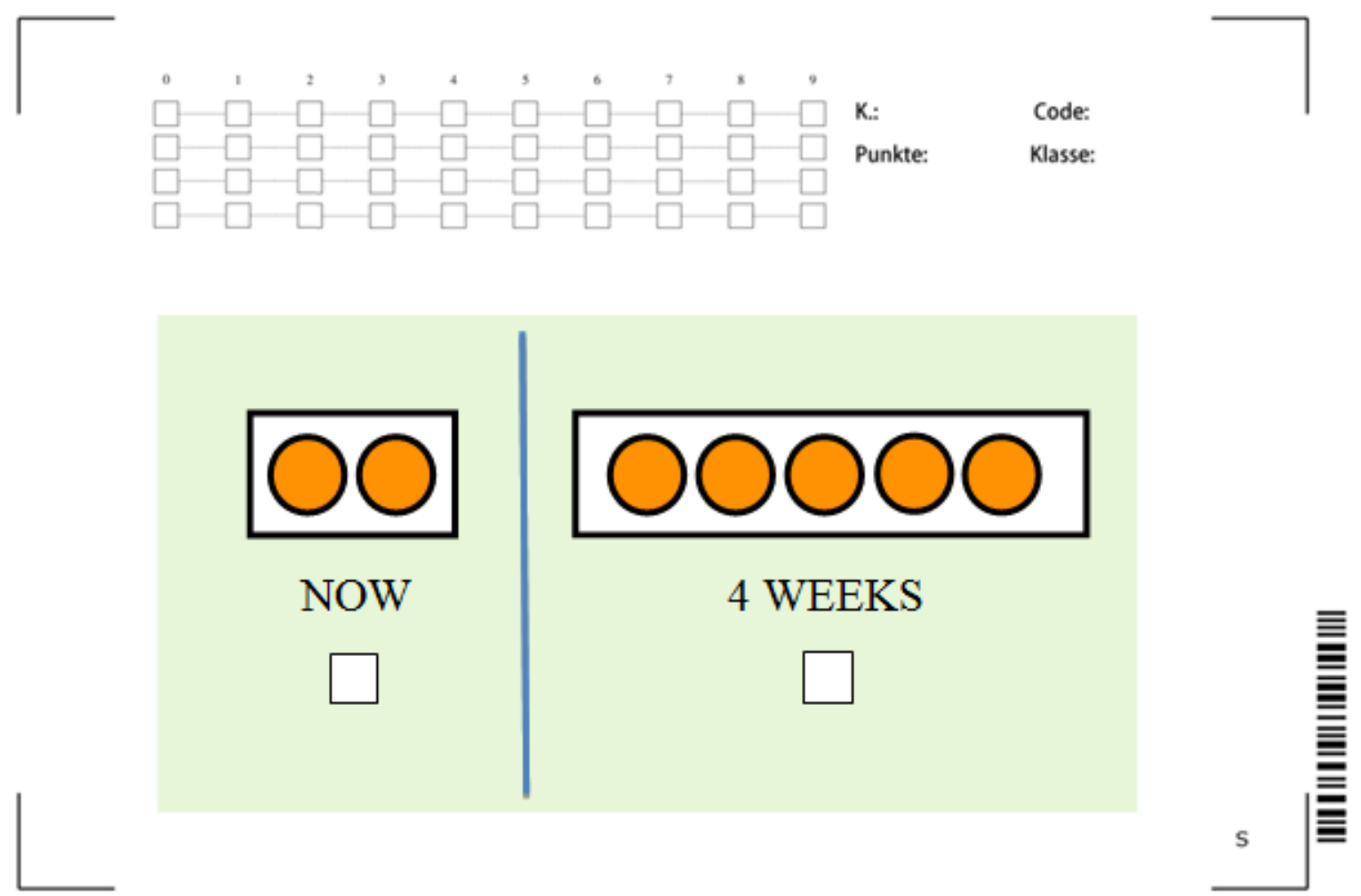




\section{Experimental Instructions for the second experiment on intertemporal choices (October}

2012)

Good morning. My name is ... Today's game works as follows:

At the beginning you will receive 5 tokens (please place the 5 tokens in front of the child). You have to decide how many of these 5 tokens you want to put in the box labeled NOW (point at the left box) and how many tokens you want to put in the box labeled " 4 WEEKS" (point at the right box). You will receive the tokens that you put in the box "NOW" immediately after the game and you can use these tokens for buying presents in our present shop. You can take these presents home today. Each token that you put in the box "4 WEEKS" will be doubled and you will receive the presents that you choose with these tokens in 4 weeks only.

Let's consider an example: If you, for instance, want to receive two tokens today, what do you have to do? (Answer of the child: "I have to put 2 tokens in the left box) And what happens with the other 3 tokens? (Answer: I have to put these tokens in the right box"; please let the child demonstrate this) How many tokens will be added to this box? (point at the right box; answer of the child: "3"; please demonstrate!) How many tokens are in the box in total? (Answer: 6). When will you receive the presents which you can choose with these 6 tokens? (Answer: in 4 weeks). And what happens if you put 5 tokens in that box? (point at the left box; Answer: then I will receive 5 tokens immediately after the game and I can choose presents with these 5 tokens which I can take home today). And what happens if you put all 5 tokens in that box? (point at the right box; Answer: then these tokens will be doubled and I can choose presents with the 10 tokens which I will receive only in 4 weeks.) Could you please repeat the rules of the game? Please take your decision now. You have to put the tokens which you want to receive today in this box (point at the left box) and the tokens with which you can buy presents which you will receive in 4 weeks in that box (point at the right box). Take as much time as you need for your decision. In the meantime I will turn around so I don't disturb you. Just call me when you are done. 
Decision sheet for the second experiment on intertemporal choices

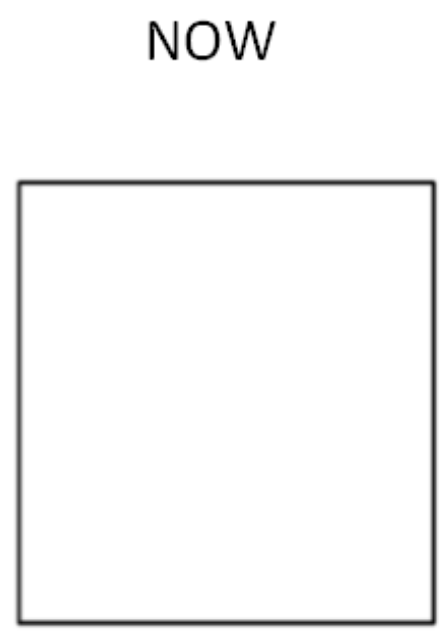

4 WEEKS

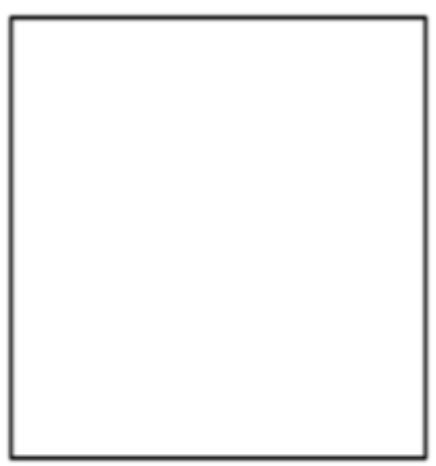




\section{Experimental Instructions “Risk attitudes” (October 2012)}

Good morning. My name is ... Today's game works as follows:

At the beginning you will receive 5 tokens (please place the 5 tokens in front of the child). You have to decide how many of these 5 tokens you want to keep for sure and with how many of these tokens you want to play the "treasure"-game. You have to put the tokens you keep for sure in this box (point at the left box). Likewise, you must put the tokens with which you want to play the treasure-game in that box (point at the right box). Each token that you put in the treasure-game will be doubled. The rules of the treasure-game are as follows: Here I have two cards. On this card you see a full treasure chest and on the other card there is an empty treasure chest (show the respective cards). I will mingle the two cards under the table and then I will put the cards on the table upside down (please demonstrate; Attention: you have to mingle the cards, such that the child is not able to see the picture on the respective card). Then you can draw one of the cards. If you, for example, draw the full treasure chest, (point at the full treasure chest on the decision sheet), then you will receive all the tokens from this box. On the other hand, if you draw the empty treasure chest (point at the empty treasure chest on the decision sheet) then you will lose all the tokens from this box. At the end you will receive the tokens that you keep for sure (point at the left box) and the tokens that you win in the treasure game (point at the right box).

Let's consider an example: If you, for instance, want to keep one token for sure and play the treasure-game with the other 4 tokens, what do you have to do? (Answer of the child: "I have to put 1 token in the left box and 4 tokens in the right box"; please let the child demonstrate this) How many tokens will be added to this box? (point at the right box; answer of the child: "4"; please demonstrate!) What happens next? How does the treasure-game work? (Child has to repeat the rules of the game). How many tokens will you win if you draw the full treasure chest? (Answer of the child: "8 tokens"). And how many tokens will you receive in total? (Answer of the child: “9”). Exactly. You will receive 8 tokens from the treasure-game plus 1 additional token which you kept for sure. What happens if you draw the empty treasure chest? (Answer of the child: "I lose all the tokens of the treasure-game") Exactly. How many tokens will you receive in total? (Answer of the child: “1”) Exactly. This was only an example. Let's consider another example: Could you please explain the rules of the game if you want to keep 4 tokens for sure and play the treasure-game with 1 token? (The child has to recapitulate the game with the new example). What happens if you, for instance, put all your 5 tokens in this box? (point at the right box; let the child recapitulate the game) What happens if you, for 
instance, put all your 5 tokens in this box? (point at the left box; let the child recapitulate the game). Could you please repeat the rules of the game?

Please take your decision now. You have to put the tokens which you want to keep for sure in this box (point at the left box) and the tokens with which you want to play the treasure-game have to be put in that box (point at the right box). Take as much time as you need for your decision. In the meantime I will turn around so I don't disturb you. Just call me when you are done. 
Decision sheet for the risk experiment

$\mid$
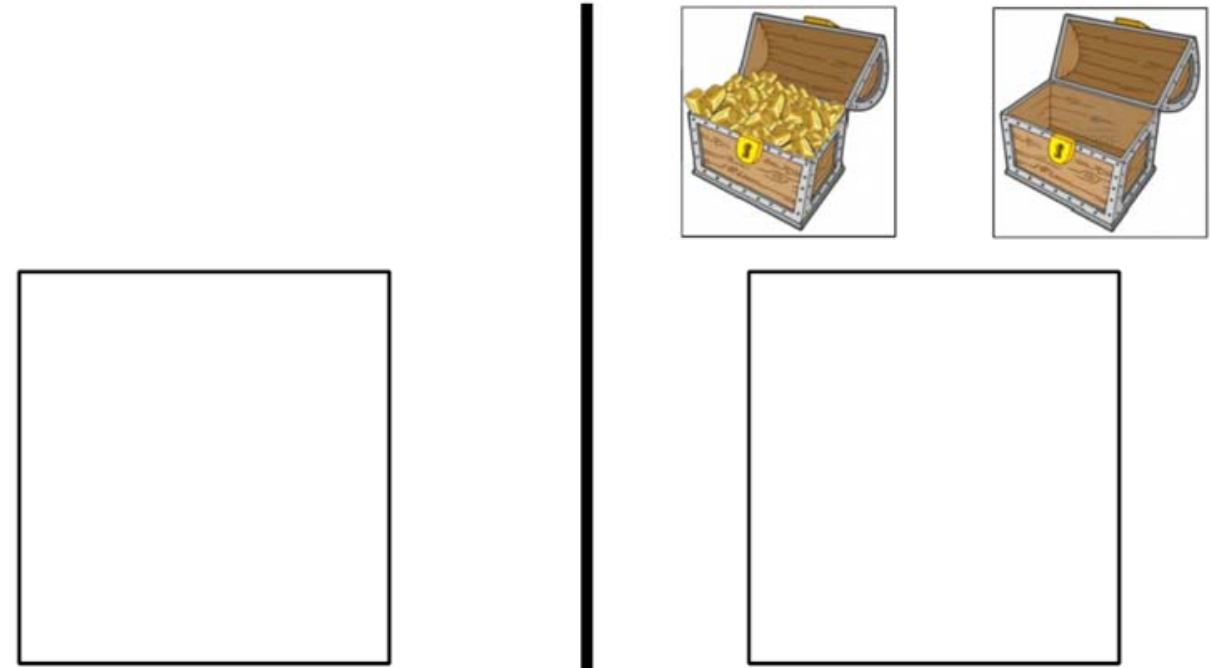


\section{Questionnaire among 177 citizens of Meran (September 2013)}

The questionnaire was run in September 2013 in the city of Meran. Bilingual student helpers asked people on the street to participate. As a selection criterion, we asked potential respondents whether they were residents of Meran. Respondents answered the questions themselves by filling in their answers on a sheet of paper. On average, it took respondents less than five minutes to complete the survey. We collected data for 90 Italian-speaking residents of Meran, and 87 German-speaking ones. Both groups do not differ significantly in their answers to the demographic background questions 11 to 15. Concerning gender, we have relatively more female and less male respondents in the German-speaking group.

In the following, we present an English translation of the German, respectively Italian, survey.

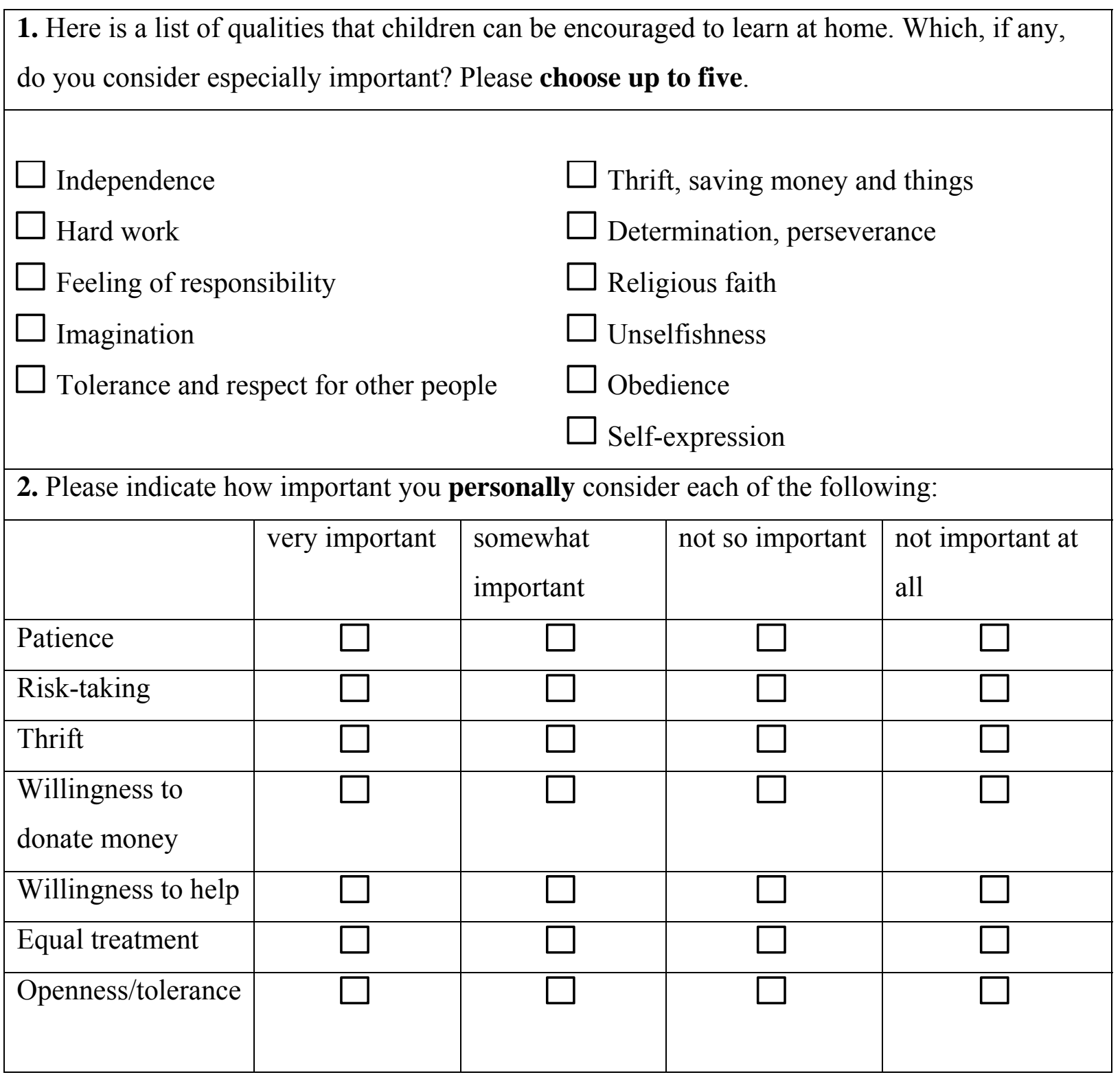




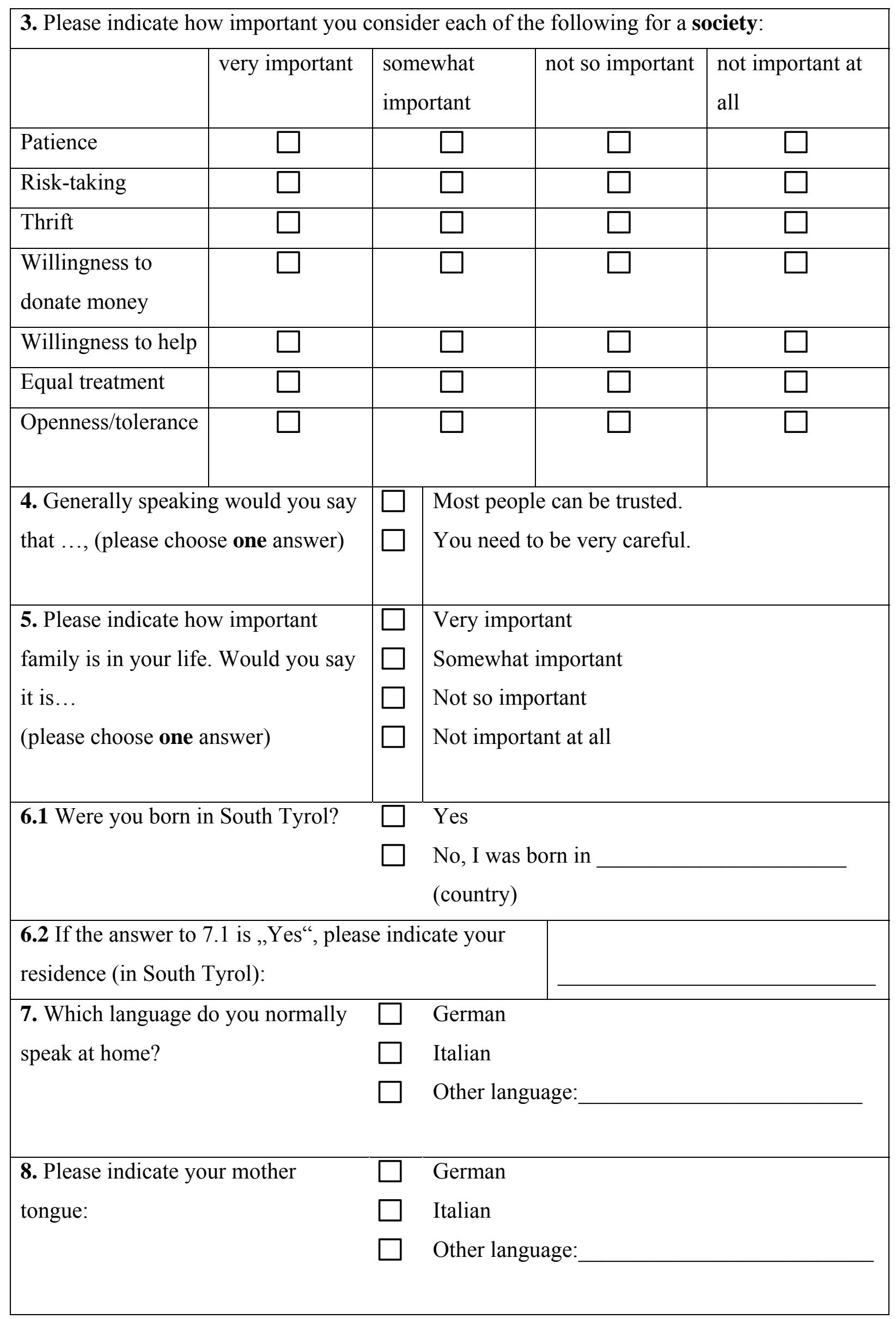




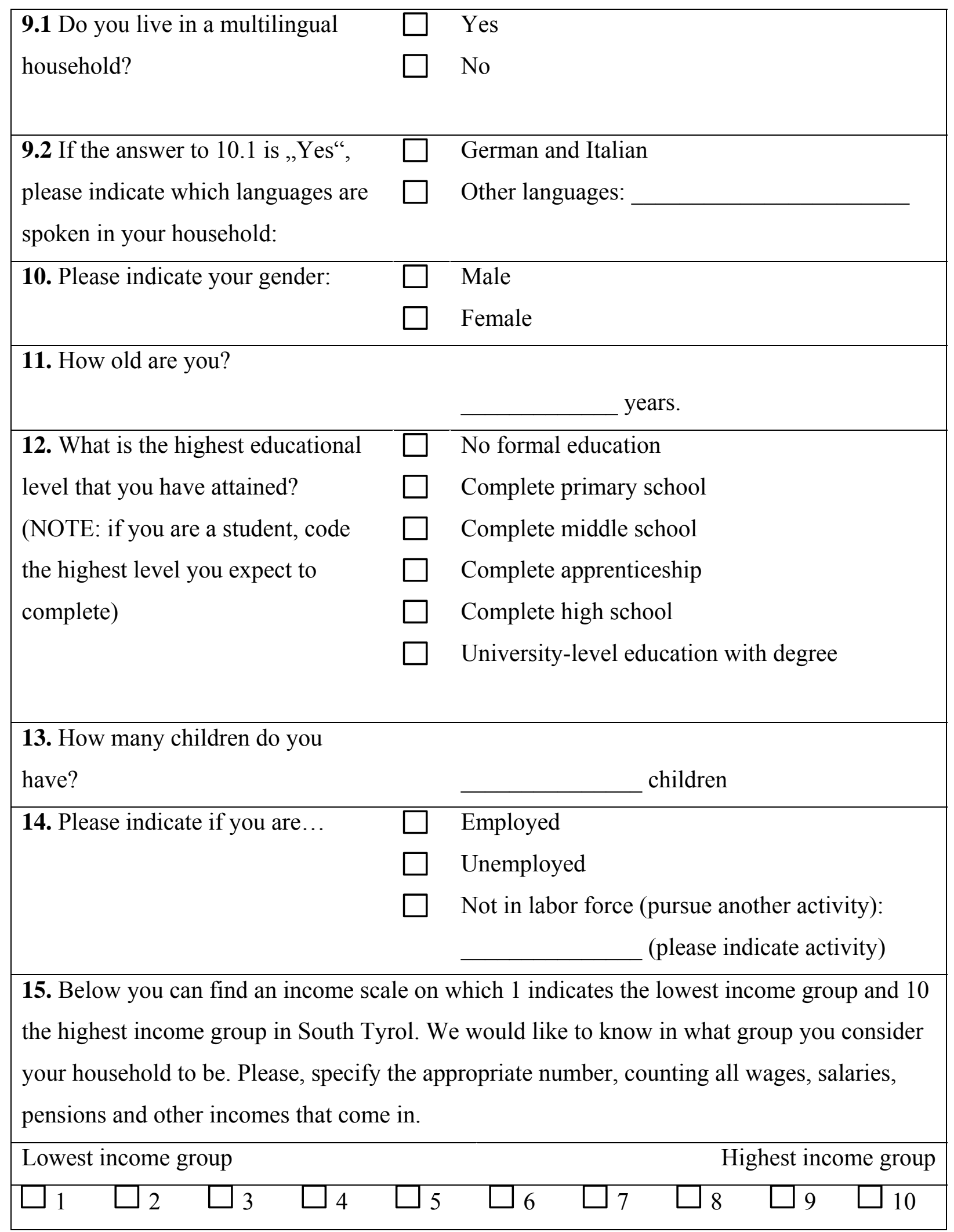

